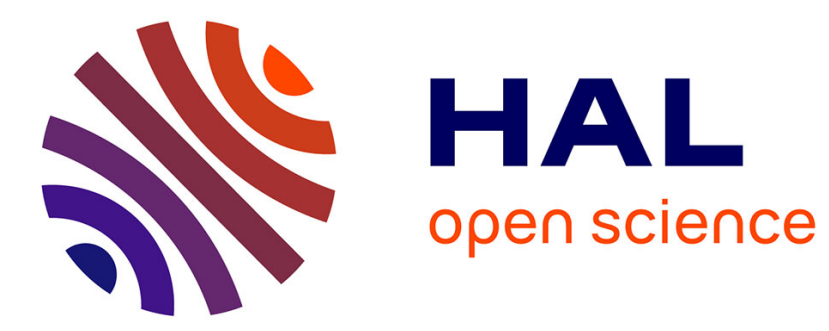

\title{
Constrained hierarchical twinning in Ru-based high temperature shape memory alloys
}

Anna M. Manzoni, Anne Denquin, Philippe Vermaut, Frédéric Prima, Inés Puente-Orench, Christoph Pauly, Frank Mücklich, Richard A. Portier

\section{To cite this version:}

Anna M. Manzoni, Anne Denquin, Philippe Vermaut, Frédéric Prima, Inés Puente-Orench, et al.. Constrained hierarchical twinning in Ru-based high temperature shape memory alloys. Acta Materialia, 2016, 111, pp.283-296. 10.1016/j.actamat.2016.03.067 . hal-01714576

\author{
HAL Id: hal-01714576 \\ https://hal.science/hal-01714576
}

Submitted on 4 Oct 2021

HAL is a multi-disciplinary open access archive for the deposit and dissemination of scientific research documents, whether they are published or not. The documents may come from teaching and research institutions in France or abroad, or from public or private research centers.
L'archive ouverte pluridisciplinaire HAL, est destinée au dépôt et à la diffusion de documents scientifiques de niveau recherche, publiés ou non, émanant des établissements d'enseignement et de recherche français ou étrangers, des laboratoires publics ou privés. 


\title{
Constrained hierarchical twinning in Ru-based high temperature shape memory alloys
}

\author{
Anna M. Manzoni ${ }^{\text {a, }}$, Anne Denquin ${ }^{\text {a }}$, Philippe Vermaut ${ }^{\text {b, }}$, Frédéric Prima ${ }^{b}$, \\ Inés Puente-Orench ${ }^{\mathrm{d}, \mathrm{e}}$, Christoph Pauly ${ }^{\mathrm{f}}$, Frank Mücklich ${ }^{\mathrm{f}}$, Richard A. Portier ${ }^{\mathrm{b}}$ \\ a ONERA 29 Avenue de la Division Leclerc, B.P. 72, 92322 Châtillon, France \\ b Chimie ParisTech, PSL Research University, CNRS, Institut de Recherche de Chimie Paris (IRCP), F-75005 Paris, France \\ c Sorbonne Universities, UPMC University Paris 06, UFR926, 75005 Paris, France \\ ${ }^{\mathrm{d}}$ Institut Laue Langevin, 6 rue Jules Horowitz, Grenoble 38042, France \\ e Instituto de Ciencia de Materiales de Aragon, ICMA-CSIC, Pedro Cerbuna 12, 50009 Zaragoza, Spain \\ ${ }^{\mathrm{f}}$ Functional Materials, Materials Science Department, Saarland University, Saarbrücken D-66123, Germany
}

The microstructure of high temperature shape memory alloys of the Ru-Ta and Ru-Nb family are investigated in detail. After cooling from the high temperature cubic $\beta$ phase the off-stoichiometric alloys show a compound twinning in the tetragonal $\beta^{\prime}$ phase which prevails at room temperature and can be observed as two levels of laminates $A$ and $C$ [1]. The stoichiometric alloys are characterized by a second phase transformation from $\beta^{\prime}$ to monoclinic $\beta^{\prime \prime}$, which adds another type of twinning. The latter belongs to the monoclinic $\mathrm{P} 2 / \mathrm{m}$ structure and has been created out of one of the lost symmetry elements from the tetragonal $\mathrm{P} 4 / \mathrm{mmm}$ phase during the $\beta^{\prime} \rightarrow \beta^{\prime \prime}$ transformation. The unusual characteristic of this new twinning, called $\mathrm{B}$, is the fact that it has an intermediate size between the $\mathrm{A}$ and $\mathrm{C}$ twins that belong to the high-temperature transformation $\beta^{\prime} \rightarrow \beta^{\prime \prime}$. This is due to a second constrained martensitic transformation.

\section{Introduction}

Their ability for sensing and actuating functions have enabled shape memory alloys to be of use in various technological application, such as medical stents, glasses frames or self-opening space antennae. Their commercial use has until now been limited to temperatures below $100^{\circ} \mathrm{C}$.

An overview over high temperature shape memory alloys has recently been given in Ref. [1] and it contains information on shape memory systems such as (with increasing application temperatures) Ti-Ni-Pd [2,3], Cu-based [4,5], Co-based [6], Ti-Pd [2,7], Ptbased $[2,8]$ and Ru-based alloys [9,10] for the highest temperature applications. This list is far from being exhaustive.

The shape memory properties make these alloys potential

\footnotetext{
* Corresponding author.

E-mail addresses: anna_manzoni@gmx.net (A.M. Manzoni), anne.denquin@ onera.fr (A. Denquin), philippe-vermaut@chimie-paristech.fr (P. Vermaut), frederic-prima@chimie-paristech.fr (F. Prima), puenteorench@ill.fr (I. PuenteOrench), c.pauly@mx.uni-saarland.de (C. Pauly), muecke@matsci.uni-sb.de (F. Mücklich), richard-portier@chimie-paristech.fr (R.A. Portier).
}

candidates for applications in turbo jet engines, and among the few shape memory alloys with martensitic transformation temperatures above $800{ }^{\circ} \mathrm{C}$ Ru-based alloys Ru-Ta and Ru-Nb take a prominent place [1,10-12]. Both alloy families are characterized by two successive phase transformations from cubic to tetragonal and then to monoclinic, as long as the composition is close to the equiatomic. Both transformations are accompanied by a shape memory effect, even though the low-temperature transformation has a greater impact $[13,14]$. The important parts of the phase diagrams of the two families as well as the DSC curves that give information on the transformation temperatures are given in Fig. 1.

The equiatomic alloys are characterized by two successive transformations $\beta \rightarrow \beta^{\prime} \rightarrow \beta^{\prime \prime}$. The alloys with 45 and $43 \%$ Ru show only the high temperature transformation $\beta \rightarrow \beta^{\prime}$. The high temperature phase $\beta$ has a cubic B2 structure, the $\beta^{\prime}$ phase is tetragonal and the low temperature phase $\beta^{\prime \prime}$ is monoclinic. For more details see Ref's [11,13-16]. The structure of the $\beta^{\prime \prime}$ phase has initially given by Fonda et al. [17] and is being adapted in a parallel paper in order to explain the superstructure that is visible in diffraction experiments. The positions of the atoms in the big monoclinic cell differ 
a)

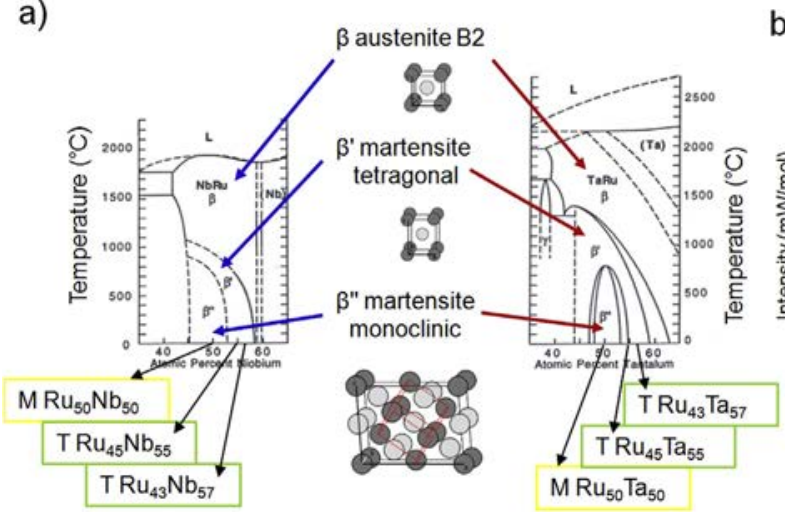

b)

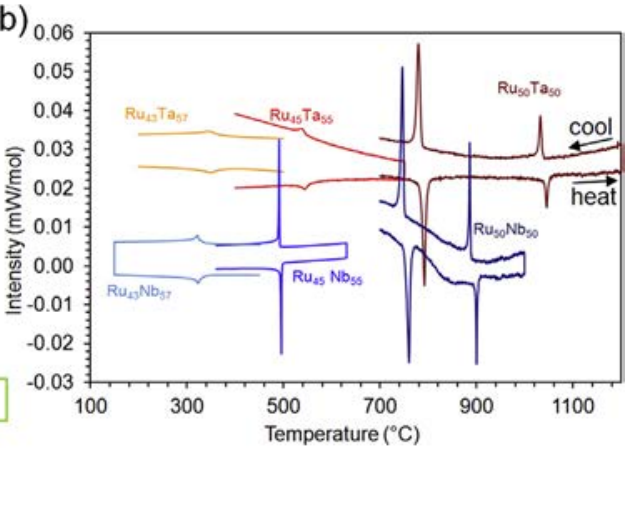

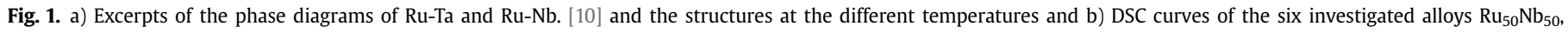
$\mathrm{Ru}_{45} \mathrm{Nb}_{55}, \mathrm{Ru}_{43} \mathrm{Nb}_{57}$ and $\mathrm{Ru}_{50} \mathrm{Ta}_{50}, \mathrm{Ru}_{45} \mathrm{Ta}_{55}$ and $\mathrm{Ru}_{43} \mathrm{Ta}_{57}$ [14]. T stands for tetragonal and $\mathrm{M}$ for monoclinic.

slightly from a perfect linear alignment.

In order to acquire an exhaustive understanding of the microstructure, the alloys have been investigated with scanning electron microscopy, transmission electron microscopy, neutron diffraction and electron backscatter diffraction. Results have been combined with data from former investigations with differential scanning calorimetry and x-ray diffraction. This combination of methods allows making a direct connection between the structure at different temperatures, the misorientation of the different areas in the microstructure, the morphology and, most of all, the evolution of the three aforementioned aspects.

The alloys with two transformations show three scales of twinning whereas the alloys with only one phase transformation show two or sometimes even only one scales of twinning.

It has thus been supposed that the low temperature transformation adds one scale of twinning. The room temperature microstructure of all six alloys has been observed in terms of twinning size, twinning scales, misorientation between same order twins and different order twins. The well-known $\{101\}_{\mathrm{T}}$ compound twinning, which has been shown before $[10,11,15,16]$, is present in all investigated alloys, but it will be completed by a second type of twinning in the equiatomic alloys, which is unique in its way of forming inside an already existing twinned microstructure.

This article aims at explaining of the unusual microstructural changes that are created by the low temperature transformation $\beta^{\prime} \rightarrow \beta^{\prime \prime}$.

\section{Experimental procedures}

Alloys were prepared from elements of commercial purity in a vacuum arc melting furnace. Ingots were remelted several times in order to ensure homogeneity and then homogenized at $1600^{\circ} \mathrm{C}$ for $168 \mathrm{~h}$.

Specimens for scanning electron microscopy (SEM) observations were grinded and polished down to a final polishing with an OP-U colloidal silica suspension with grain size $50 \mathrm{~nm}$. Specimens for electron backscattered diffraction (EBSD) observations were polished additionally for $3 \mathrm{~h}$ on a vibrant polishing table.

Specimens for transmission electron microscopy (TEM) observations were ground down to a thickness of $140 \mu \mathrm{m}$ and then electropolished in a Tenupol with a polishing solution $80 \%$ methanol and $20 \% \mathrm{H}_{2} \mathrm{SO}_{4}$ at $-20{ }^{\circ} \mathrm{C}$.

The SEMs used in this work were a Zeiss DSM962 system with an acceleration voltage of $15 \mathrm{kV}$, a FEI StrataTM DB 235 FIB/SEM with an accelerating voltage of $20 \mathrm{kV}$ and a FEI Helios Nanolab600 FIB/SEM, both equipped with an EDAX Hikari EBSD detector. The
TEM was a Philips CM20 microscope with an acceleration voltage of $200 \mathrm{kV}$.

Neutron diffraction experiments were carried out at the D20 beamline at the ILL in Grenoble. The detector was a position sensitive detector with an angular range of $153^{\circ}$ in $2 \theta$. The wavelength was $0.13 \mathrm{~nm}$ and the flux $9.8 \times 10^{7} \mathrm{n} \mathrm{cm}^{-2} \mathrm{~s}^{-1}$. A data calibration has been performed using a Si sample for the correct determination of the wavelength and NAC for the instrumental resolution function. Specimens were heated in-situ in a vacuum furnace. The temperature observations cover a range from room temperature up to about $1100{ }^{\circ} \mathrm{C}$. Every 2.5 or $5^{\circ} \mathrm{C}$ a spectrum has been recorded for about $\sim 5 \mathrm{~min}$.

X-ray diffraction gave been carried out on a Philips PW 1380 with a Bragg-Brentano configuration. The chosen wavelength is a $\mathrm{Cu} \mathrm{K} \alpha 1$ with $\lambda=0.154056 \mathrm{~nm}$.

The subsequent calculations from neutron and XRD diffraction patterns have been achieved with the help of the Fullprof program [18] and Rietveld refinement for the determination of the lattice parameters.

\section{Results and discussion}

\subsection{Overview and general results}

In order to understand the microstructural evolution of these $\mathrm{Ru}-\mathrm{Ta}$ and $\mathrm{Ru}-\mathrm{Nb}$ alloys it is necessary to be aware of the direct lattice parameters of all alloys at room temperature. They were determined by X-ray diffraction ( $\mathrm{Ru}_{43} \mathrm{Ta}_{57}$ and $\left.\mathrm{Ru}_{43} \mathrm{Ta}_{57}\right)$ or neutron diffraction ( $\mathrm{Ru}_{45} \mathrm{Ta}_{55}, \mathrm{Ru}_{50} \mathrm{Ta}_{50} \mathrm{Ru}_{45} \mathrm{Nb}_{55}$ and $\left.\mathrm{Ru}_{50} \mathrm{Nb}_{50}\right)$ and they are summarized in Table 1.

Fig. 2 shows SEM micrographs at two different magnifications of six alloys of the Ru-Ta and Ru-Nb families, namely $\mathrm{Ru}_{43} \mathrm{Ta}_{57}$, $\mathrm{Ru}_{45} \mathrm{Ta}_{55}$ and $\mathrm{Ru}_{50} \mathrm{Ta}_{50}$ and $\mathrm{Ru}_{43} \mathrm{Nb}_{57}, \mathrm{Ru}_{45} \mathrm{Nb}_{55}$ and $\mathrm{Ru}_{50} \mathrm{Nb}_{50}$. The equiatomic alloys $\mathrm{Ru}_{50} \mathrm{Ta}_{50}$ and $\mathrm{Ru}_{50} \mathrm{Nb}_{50}$ show three levels of twinning called $\mathrm{A}$ (about $10 \mu \mathrm{m}$ in size), $\mathrm{B}$ (about $7 \mu \mathrm{m}$ in size) and $\mathrm{C}$

Table 1

Direct lattice parameters of $\mathrm{Ru}_{43} \mathrm{Ta}_{57}, \mathrm{Ru}_{45} \mathrm{Ta}_{55} \mathrm{Ru}_{50} \mathrm{Ta}_{50}, \mathrm{Ru}_{43} \mathrm{Nb}_{57}, \mathrm{Ru}_{45} \mathrm{Nb}_{55}$ and $\mathrm{Ru}_{50} \mathrm{Nb}_{50}$ at room temperature RT $[13,14]$.

\begin{tabular}{lllllll}
\hline & Structure at RT & $\mathrm{a}[\mathrm{nm}]$ & $\mathrm{b}[\mathrm{nm}]$ & $\mathrm{c}[\mathrm{nm}]$ & $\beta_{\mathrm{M}}\left[^{\circ}\right]$ & $\mathrm{c} / \mathrm{a}$ \\
\hline $\mathrm{Ru}_{43} \mathrm{Ta}_{57}$ & Tetragonal P4/mmm & 0.3120 & 0.3120 & 0.3270 & - & 1.0481 \\
$\mathrm{Ru}_{45} \mathrm{Ta}_{55}$ & Tetragonal P4/mmm & 0.3100 & 0.3100 & 0.3300 & - & 1.0645 \\
$\mathrm{Ru}_{50} \mathrm{Ta}_{50}$ & Monoclinic P2/m & 0.8023 & 0.4370 & 0.5397 & 96.40 & - \\
$\mathrm{Ru}_{43} \mathrm{Nb}_{57}$ & Tetragonal P4/mmm & 0.3130 & 0.3130 & 0.3310 & - & 1.0575 \\
$\mathrm{Ru}_{45} \mathrm{Nb}_{55}$ & Tetragonal P4/mmm & 0.3110 & 0.3110 & 0.3300 & - & 1.0611 \\
$\mathrm{Ru}_{50} \mathrm{Nb}_{50}$ & Monoclinic P2/m & 0.8049 & 0.4376 & 0.5411 & 96.56 & - \\
\hline
\end{tabular}




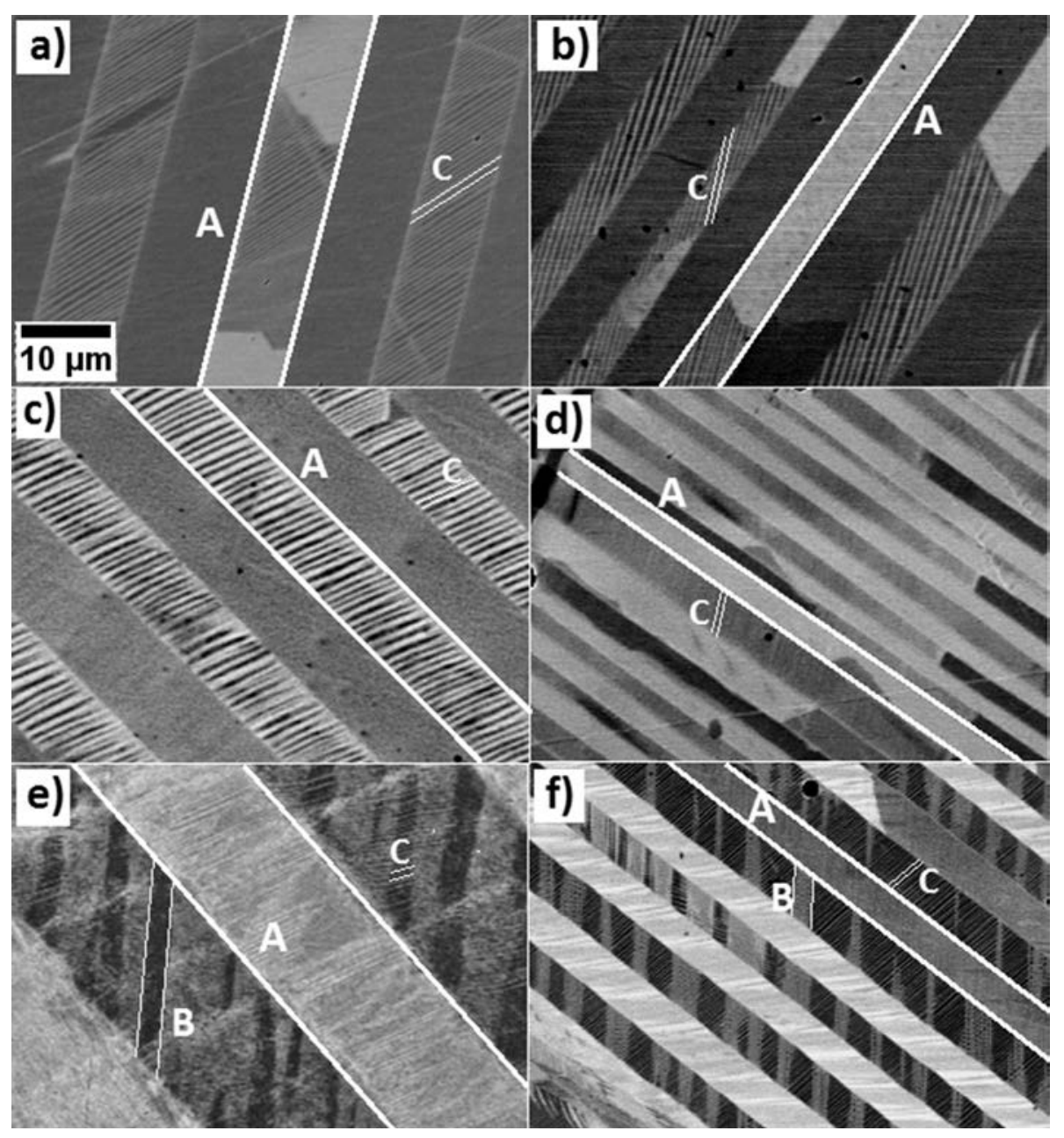

Fig. 2. SEM micrographs of six alloys a) $\left.R u_{43} T_{57}, c\right) R u_{45} T a_{55}$ and e) $R u_{50} T_{50}$ and b) $R u_{43} N_{57}$, d) $R u_{45} N b_{55}$ and f) $R u_{50} N b_{50}$.

(about $50 \mathrm{~nm}$ in size). The off-stoichiometric alloys $\mathrm{Ru}_{43} \mathrm{Ta}_{57}$, $\mathrm{Ru}_{45} \mathrm{Ta}_{55}, \mathrm{Ru}_{43} \mathrm{Nb}_{57}$ and $\mathrm{Ru}_{45} \mathrm{Nb}_{55}$ show only the levels $\mathrm{A}$ and $\mathrm{C}$. Even at this scale it can be seen that the density of twinning planes is highest in the stoichiometric alloys.

Based on these observations, the phase diagram and the DSC results shown in Fig. 1 [9,13], some symmetry considerations have to be made in order to link the two or three structural phases the alloys cross during the cooling from their liquid state. Group theory can be used for expressing the formation of different variants, different twins and the difference of twins and variants.

\subsection{Variants and general considerations of the martensites in $R u$ - based alloys}

\subsubsection{Variants versus twins}

3.2.1.1. Variants generated from a structural phase transformation. The role of symmetry in the study of phase transitions is well recognized for the description of the microstructure of the transformed phase. The basic idea is essentially that the total symmetry of the resulting morphology reflects the symmetry of the originating process (Curie's law). The first step consists in determining the number of generated variants and the nature of the interfaces between them. Symmetries involved through two basic groups can be described as the symmetry group of the parent crystal $G_{0}$ which is a space group or a point group if one is only interested in symmetry orientation, and the symmetry group of the external medium
G which reflects the anisotropy of the solicitation applied to the crystal and leading to the transition when a critical value is reached. This last group can be continuous. If the solicitation is the temperature, its invariance group is the symmetry group of a sphere $\left(\mathrm{SO}_{3}\right)$; if it is an applied stress field along a direction $\mathrm{n}$, its invariance group is that of a cylinder ( $\mathrm{D} \infty \mathrm{h})$. All thermodynamical properties of the transformation are invariant through any symmetry elements belonging simultaneously to both groups, the intersection group $H_{0}=G_{0} \cap G$ which is mathematically considered as the kernel of the transition. That means that if a certain embryo of the transformed phase is formed somewhere, any other embryos deduced from the first one through the operations of $\mathrm{H}_{0}$ are strictly equivalent. Thus $\mathrm{H}_{0}$ is called the group of isoprobability of nucleation of the transformation product.

Once the embryo has formed, further growth will lead to the new structure of space group $G_{1}$ with a specific orientation of $G_{1}$ with respect to $G_{0}$ and the existence of the hetero-phase interfaces between the two structures. Certain embryos in contact after growing would form a single crystal, whereas other with space groups differing in orientation-translation would form a bi-crystal and would be separated by a homophase interface. In order to numerate all the different variants of the transformed phase, one has to select in $\mathrm{H}_{0}$ all the subset of elements which do not belong to $\mathrm{G}_{1}$. This is performed by considering the new intersection group, $\mathrm{N}_{01}=\mathrm{H}_{0} \cap \mathrm{G}_{1}$ which is the set of symmetry elements common to both $\mathrm{H}_{0}$ and $\mathrm{G}_{\mathrm{I}}$. Now, the number, $\mathrm{n}_{01}$ of different possible variants 
of the $G_{1}$ product phase is given by the number of times $N_{01}$ is contained into $\mathrm{H}_{0}$. Mathematically, $\mathrm{n}_{01}$ is the index of the subgroup $\mathrm{N}_{01}$ into $\mathrm{H}_{0}$, it is the number of $\mathrm{N}_{01}$ co-sets onto $\mathrm{H}_{0}$. The complete group-tree characterizing the transition from $G_{0}$ to $G_{1}$ is sketched in Fig. 3 with the case of a transformation induced by temperature for which the solicitation invariant group is the group of the sphere.

In many cases, there is a group-subgroup relationship between the parent phase and the product and then, $N_{01}=G_{0} \cap G_{1}=G_{1}$ for a transformation induced by temperature.

There is an important distinction between domains and variants: every domain belongs to one kind of variant. All possible generated variants can be numbered but the number of domains will depend on the actual conditions of the transformation. For a polycrystal parent phase, the group-tree has to be considered for every grain.

The most general isometry in space is written $(\alpha \mid \tau)$ where $\alpha$ is a point operation (identity, inversion, rotation, rotation-inversion) and $\tau$ the associated translation (Seitz notation). If two crystals are related by such an operation, it means the homologous points $\mathbf{r}_{1}$, belonging to crystal 1 and $\mathbf{r}_{2}$, belonging to crystal 2 are such as $\mathbf{r}_{2}=(\alpha \mid \tau) \mathbf{r}_{1}$. If the space group of crystal 1 is $G_{1}$, the space group of crystal 2 is conjugated by $(\alpha \mid \tau), G_{2}=(\alpha \mid \tau) G_{1}(\alpha \mid \tau)^{-1}$. The operation $(\alpha \mid \tau)$ characterises the homo-phase interface. As a crystal is invariant through any operation of its space group, an operation of crystal 1 by any operation belonging to $G_{1}$ followed another by $(\alpha \mid \tau)$ leads to the same crystal 2 . Thus a homophase interface operation is characterized by a co-set: the right product of the operation $(\alpha \mid \tau)$, initially chosen by the space group of the crystal, $(\alpha \mid \tau) G_{1}$ (see Fig. 4). Obviously, all the operations of every co-set were symmetry operations of the parent phase and have been lost during the transformation. The actual shape of the interface between the two variants has not been considered up to now.

3.2.1.2. Twins. The definition of twinning as given by Hall [19] is the following: twinned and untwinned parts of a crystal (two variants) are mirror reflection of each other according to a certain plane of the crystal, which is called the composition plane. The positions of the atoms in the twinned crystal are obtained by a homogeneous shearing parallel to the composition plane. The twinning relationship between two crystals generates a coherent planar interface which is parallel to the support of the mirror. Twins are generated by deformation, recrystallization and phase

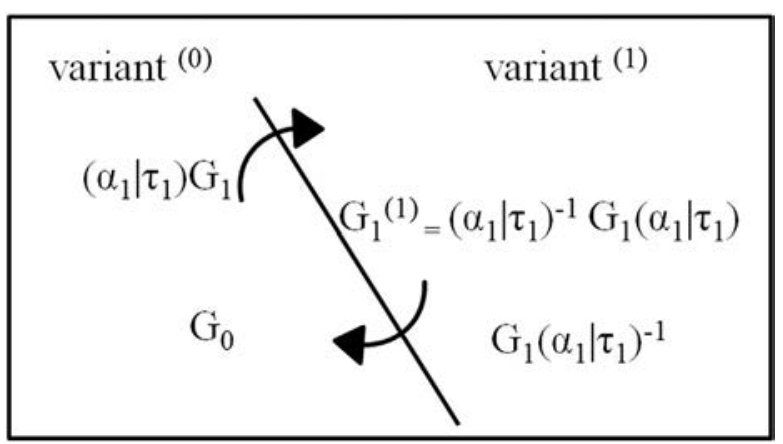

Fig. 4. Schematic description of the relations between two variants.

transformations.

\subsubsection{Martensitic transformation}

A first order structural transformation is controlled by nucleation and growth of the product phase with the formation of hetero-phased interfaces. A second order phase transformation is continuous without any coexistence of the parent phase and the product phase.

Solid state structural phase transformations are classified into two categories, namely reconstructive and displacive ones. In the former case, atomic movements are governed by the diffusion mechanism and they are thermally activated. In the latter case, the transformation is diffusionless. Atomic displacements responsible for the lattice deformation are smaller than one interatomic distance; they occur cooperatively and they do not require any thermal activation. The martensitic transformation is a first order displacive phase transformation with a homogeneous lattice deformation involving a shear-dominant shape change. The parent phase may coexist with the product and two kinds of interfaces have to be considered: homo-phase interfaces between two variants of martensite and hetero-phase interfaces between martensite and parent phases.

In every grain of the high temperature phase, called austenite, there is a finite number of crystallographically and thermodynamically equivalent paths that realize the transformation which generates a finite number of variants of the low temperature phase,

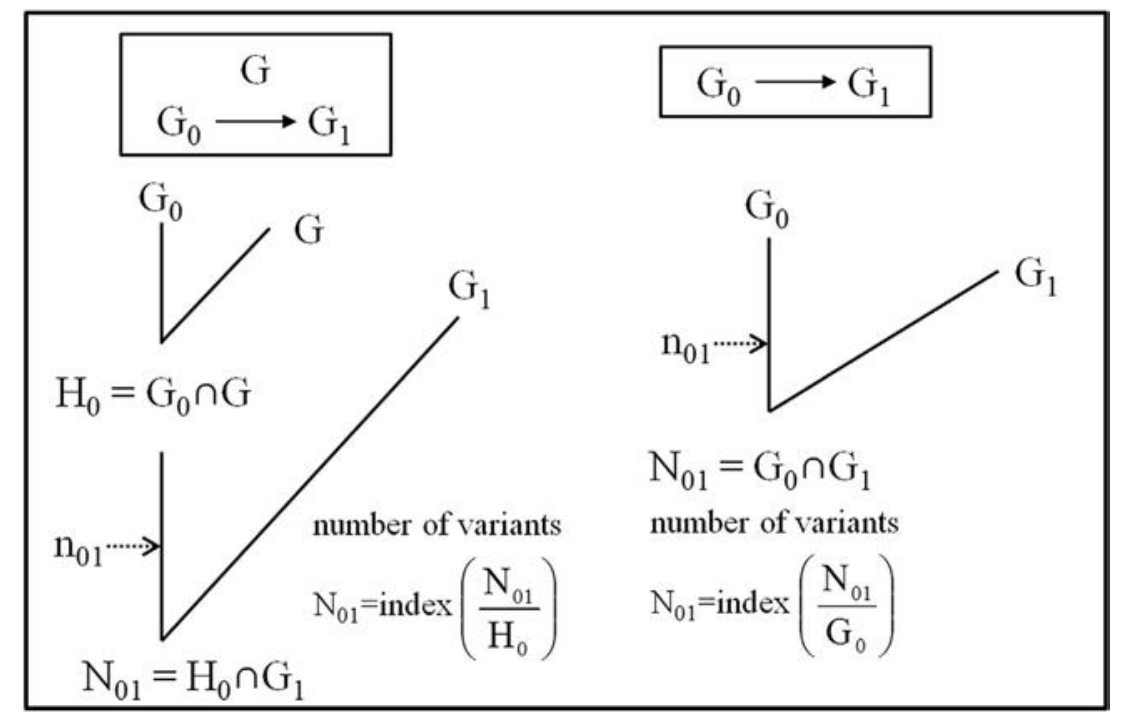

Fig. 3. Group-tree characterisation of a phase transformation. 
called martensite. All the variants have the same probability of nucleation, but, every variant being associated with a specific shape change, a stress field will be generated and it has to be accommodated by its environment. This is the reason for the formation of the so-called self accommodated groups in which selected variants are able to mutually accommodate one another. In this thermo-elastic martensitic transformation the formation of self accommodated group associated with an inhomogeneous lattice deformation drastically reduces the shape-change. But even in this case, the kinetics and the morphology of this transformation are dominated by the elastic deformation energy. This energy is stored by the specimen during cooling and, thus, during the martensite formation. It assists the reversion to austenite on heating, as a driving force. It has a strong influence on the behaviour of the specimen, as a consequence and as transformation properties depend on this energy (internal stress field), the microstructure, grain size, dislocation distribution, coherent or non coherent precipitation and vacancy density etc.

The martensitic transformation can also be induced by the application of an external stress field and some specific functional properties are directly derived from this property, namely superelasticity and memory effect. If some internal stress fields exist in the parent phase (elastic stress fields around coherent precipitates or generated by a training process) they will assist the martensitic transformation and some specific variants will be generated. This is at the origin of the two way memory effect.

The distribution of self-accommodated variants is the consequence of a phase transformation. However, in the case of many thermo-elastic martensitic transformations, the variants are related by a twinning relationship. They can be deduced from each other by a mirror symmetry with respect to a crystallographic plane which is parallel to the planar homo-phase interface between two variants. This means that in the co-set associated with the couple of variant, $(\alpha \mid \tau) G_{1}$, there is a mirror. Moreover, it is a mirror of the austenite parent phase, which was lost during the transformation. For a planar interface, this lost austenite mirror has been transformed into or is very close to a low indexed crystallographic plane of the martensite (for a sufficient atomic density) at the transformation temperature. If it is not the case, the mirror operation will describe the relation between the two variants, but the interface will be facetted and, macroscopically, it can never be found parallel to the support of the mirror.

For this investigation, the symmetry class (point groups) of the phases for the orientation variant generation has to be considered along with the unit cell parameters for the relation between the lost mirrors and their corresponding planes in the martensite.

\subsubsection{Cubic - tetragonal transformation $\left(\beta \rightarrow \beta^{\prime}\right)$}

The off-stoichiometric alloys with a tetragonal structure at room temperature have been observed and they will be the reference for the tetragonal microstructure of the stoichiometric alloys before the second martensitic transformation.

The variant distribution exhibits a single or double twinned microstructure. Two microstructures are observed (see Fig. 5). Fig. 5b shows two levels of laminates, large twins called $A_{\beta \rightarrow \beta^{\prime}}$ (1-20 $\mu \mathrm{m}$ width) and inside very narrow twins called $C_{\beta \rightarrow \beta^{\prime}}$ (average width $50 \mathrm{~nm}$ ), and Fig. 5a shows only the large twins $\mathrm{A}_{\beta \rightarrow \beta^{\prime}}$. The twin operation has been determined by TEM and is a compound twinning $\{101\}_{\mathrm{T}}$ (see Fig. 6), where T stands for the tetragonal phase. It must be noted that the 43 at.\% $\mathrm{Ru}$ alloys also show regions with two levels of twins, but the 45 at.\% Ru alloys do not show any regions with only one level. The difference between 45 at.\% Ru and 43 at.\% Ru alloys lies in the different c/a ratios (see Table 1): The higher c/a ratio in the 45 at.\% Ru alloys implies a higher deformation energy which must be accommodated with a larger number of twins.

3.2.3.1. Variants generated from this $\beta \rightarrow \beta^{\prime}$ transformation. The martensitic transformation is $\beta \operatorname{Pm} 3 \mathrm{~m}(\mathrm{a}, \mathrm{b}, \mathrm{c}) \rightarrow \beta^{\prime} \mathrm{P} 4 / \mathrm{mmm}$ $\left(a^{\prime}, b^{\prime}, c^{\prime}\right)$ with $a / / a^{\prime}, b / / b^{\prime}, c / / c^{\prime}$, the four fold axis of the tetragonal phase being parallel to the $c^{\prime}$ direction. In the language of point groups, this is a group - subgroup transformation (see Fig. 7). As the cubic structure has 48 symmetry elements and the tetragonal one only 16 , three variants are generated $(48 / 16=3)$ : e.g. the lost ternary axis can be written as $\mathrm{m} 3 \mathrm{~m} \rightarrow\left[1+3^{1}{ }_{[111]}+3^{2}{ }_{[111]}\right] 4 / \mathrm{mmm}$.

As there are three variants and with respect to the reference variant, two homophase interfaces exist and they are described by these two associated co-sets $3^{1}{ }_{[111]} 4 / \mathrm{mmm}$ and $\left.3^{2}{ }_{[111]}\right] 4 / \mathrm{mmm}$. Each of the 16 tetragonal symmetry operation of one co-set transforms the reference variant into the same variant, but special attention is due to the mirror operations which belong to the co-sets. Four mirrors of the austenite have been lost during the transformation. Two of them belong to the first co-set, $\mathrm{m}_{[101]}$ and $\mathrm{m}_{[10 \overline{1}]}$, the two others belong to the second co-set, $\mathrm{m}_{[011]}$ and $\mathrm{m}_{[01 \overline{1}]}$.

According to the relationship between austenite and martensite, the relationships between these lost cubic mirrors and the planes of the tetragonal phase are the following:

$$
\begin{aligned}
& \mathrm{m}_{[101] \mathrm{C}} \rightarrow(101)_{\mathrm{T}} \\
& \mathrm{m}_{[10 \overline{1}] \mathrm{C}} \rightarrow(10 \overline{1})_{\mathrm{T}} \\
& \mathrm{m}_{[011] \mathrm{C}} \rightarrow(011)_{\mathrm{T}} \\
& \mathrm{m}_{[01 \overline{1}] \mathrm{C}} \rightarrow(01 \overline{1})_{\mathrm{T}}
\end{aligned}
$$

A good fit between the lost mirror planes in the cubic $\beta$ phase and the corresponding planes in the tetragonal $\beta^{\prime}$ phase is observed at the transformation temperature and the self-accommodated microstructure is built according to this fit. Fig. 8 shows the poles of a small area of the stereographic projection of the cubic $\beta$ phase as well as the poles of the monoclinic phase at transformation temperature and at room temperature. The fit decreases during cooling, as can also be observed when looking at the c/a ratio in Fig. 9c.

The cooling down through the existence domain of the tetragonal phase induces a large evolution of the tetragonal parameter both in the stoichiometric and the non-stoichiometric alloys (see Fig. 9 and [14]) and thus a stress field is created and increased during further cooling. During the cooling the self-accommodated microstructure that had been formed at the transformation temperature has to be modified in order to relax a part of the induced stress field. In Fig. 6 the two twinned plates, equivalent at transformation temperature, have different thicknesses at room temperature, but it cannot be excluded that one residual stress field remains after cooling down inside the tetragonal domain.

\subsubsection{Off-stoichiometric alloys with only one phase transformation} $\beta \rightarrow \beta^{\prime}$. As the material only forms twins when this is energetically favourable, it is important to know the evolution of the unit cell throughout the transition from the cubic $\beta$ phase to the tetragonal $\beta^{\prime}$ phase. Fig. 9 shows the evolution of the tetragonal lattice parameters $\mathrm{c}_{\mathrm{T}}$ and $\mathrm{a}_{\mathrm{T}}$ of $\mathrm{Ru}_{45} \mathrm{Nb}_{55}$ and $\mathrm{Ru}_{45} \mathrm{Ta}_{55}$; and of the $\mathrm{c}_{\mathrm{T}} / \mathrm{a}_{\mathrm{T}}$ ratio of both $\mathrm{Ru}_{45} \mathrm{Nb}_{55}$ and $\mathrm{Ru}_{45} \mathrm{Ta}_{55}$ as determined by neutron diffraction. Even though the figure depicts the evolution duting heating, the cooling curve would be qualitatively the same, except for the hysteresis in temperature. After cooling from the cubic phase, which has only one lattice parameter $a_{c}$, the transformation $\beta \rightarrow \beta^{\prime}$ is characterized by a jump which gives birth to the parameters $\mathrm{a}_{\mathrm{T}}$ and $c_{\mathrm{T}}$. The parameter $\mathrm{c}_{\mathrm{T}}$ increases upon cooling whereas $\mathrm{a}_{\mathrm{T}}$ decreases. Thus the ratio $c_{\mathrm{T}} / \mathrm{a}_{\mathrm{T}}$ increases upon cooling, leading to an increasing 

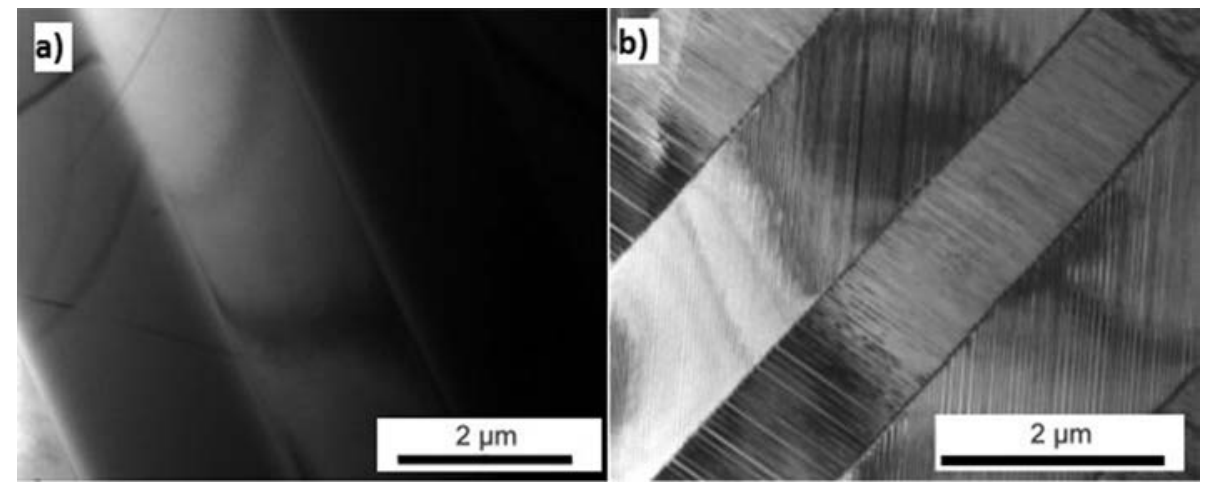

Fig. 5. $B F$ TEM of a) $\mathrm{Ru}_{43} \mathrm{Nb}_{57}$ showing only one scale of twins $A$ and $\left.b\right) \mathrm{Ru}_{45} \mathrm{Ta}_{55}$ showing two scales of twins $A$ and $C$.

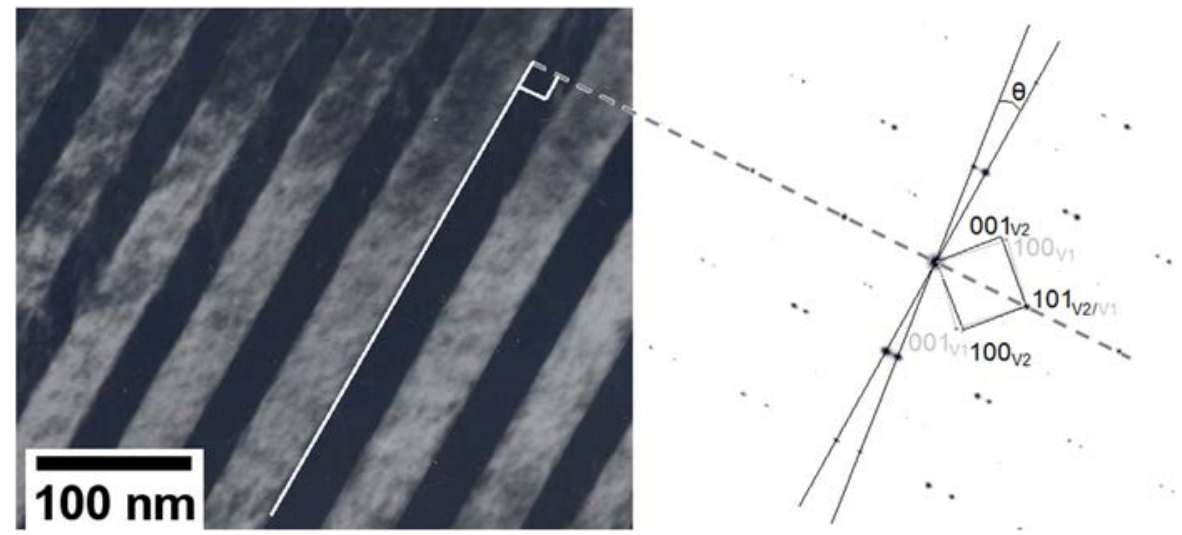

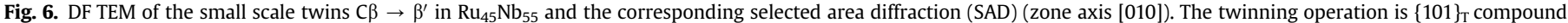
where $T$ stands for the tetragonal phase. The variants $V_{1}$ and $V_{2}$ form the tetragonal angle $\theta$ between their (011) planes [12].

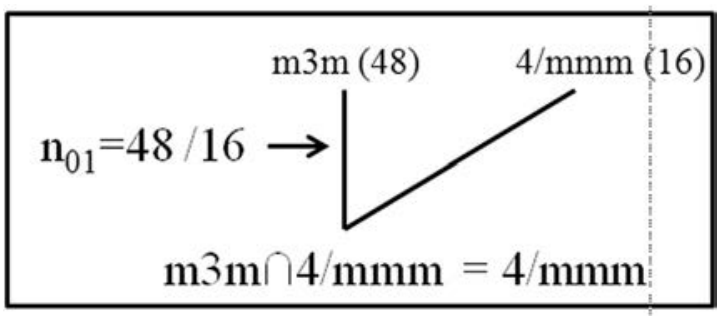

Fig. 7. Group - subgroup relationship.

need for the microstructure to balance the distortion of the lattice by an adequate variant reorganization which can lead to the formation of finer and larger twins. This need is lower in the 43 at.\% Ru alloys, because the temperature at which investigations are carried out (=room temperature) is closer to the transformation temperature and thus the lattice is less distorted. For further information the reader is invited to read Ref. [14], in which this distortion has been explained in detail for the stoichiometric alloys.

\subsubsection{Tetragonal - monoclinic transformation $\left(\beta^{\prime} \rightarrow \beta^{\prime \prime}\right)$}

The monoclinic microstructure is a multiple twinned microstructure (see Fig. 10). It consists of three levels of laminates named $A_{\beta \rightarrow \beta^{\prime}}, B_{\beta^{\prime} \rightarrow \beta^{\prime \prime}}$ and $C_{\beta \rightarrow \beta^{\prime}}$. $A_{\beta \rightarrow \beta^{\prime}}$ and $C_{\beta \rightarrow \beta^{\prime}}$ are inherited from the tetragonal microstructure and it is assumed that the microstructure of the tetragonal martensitic phase before its transformation into the monoclinic martensite is similar to the one of the tetragonal offstoichiometric alloy which has been observed at room temperature.

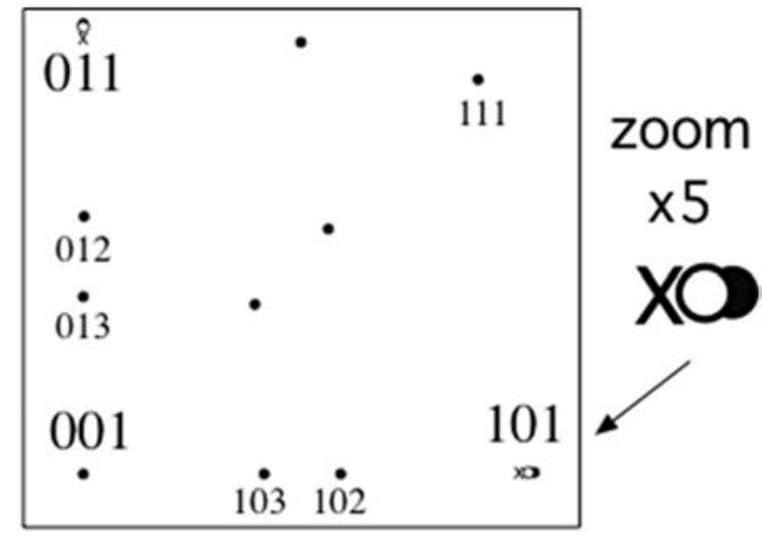

Fig. 8. Fragment of poles of the stereographic projection of the cubic $\beta$-phase $(\bullet)$ with monoclinic poles, at transformation temperature $(0)$ and at room temperature $(x)$.

$\mathrm{B}_{\beta^{\prime} \rightarrow \beta^{\prime \prime}}$ is a new level of twinning and due to the second transformation. The thickness of the $\mathrm{B}$ twins lies between the ones of $\mathrm{A}$ and $C$ (see Fig. 10).

The parameter evolution with the temperature has been analyzed in detail in Ref. [14] and it shows the expected jumps at the transformation temperature and, on cooling, a small evolution for the three basic vectors and a decrease of the $\beta$ monoclinic angle.

3.2.4.1. Variants generated from the $\beta^{\prime} \rightarrow \beta^{\prime \prime}$ transformation. The second martensitic transformation with the relative 

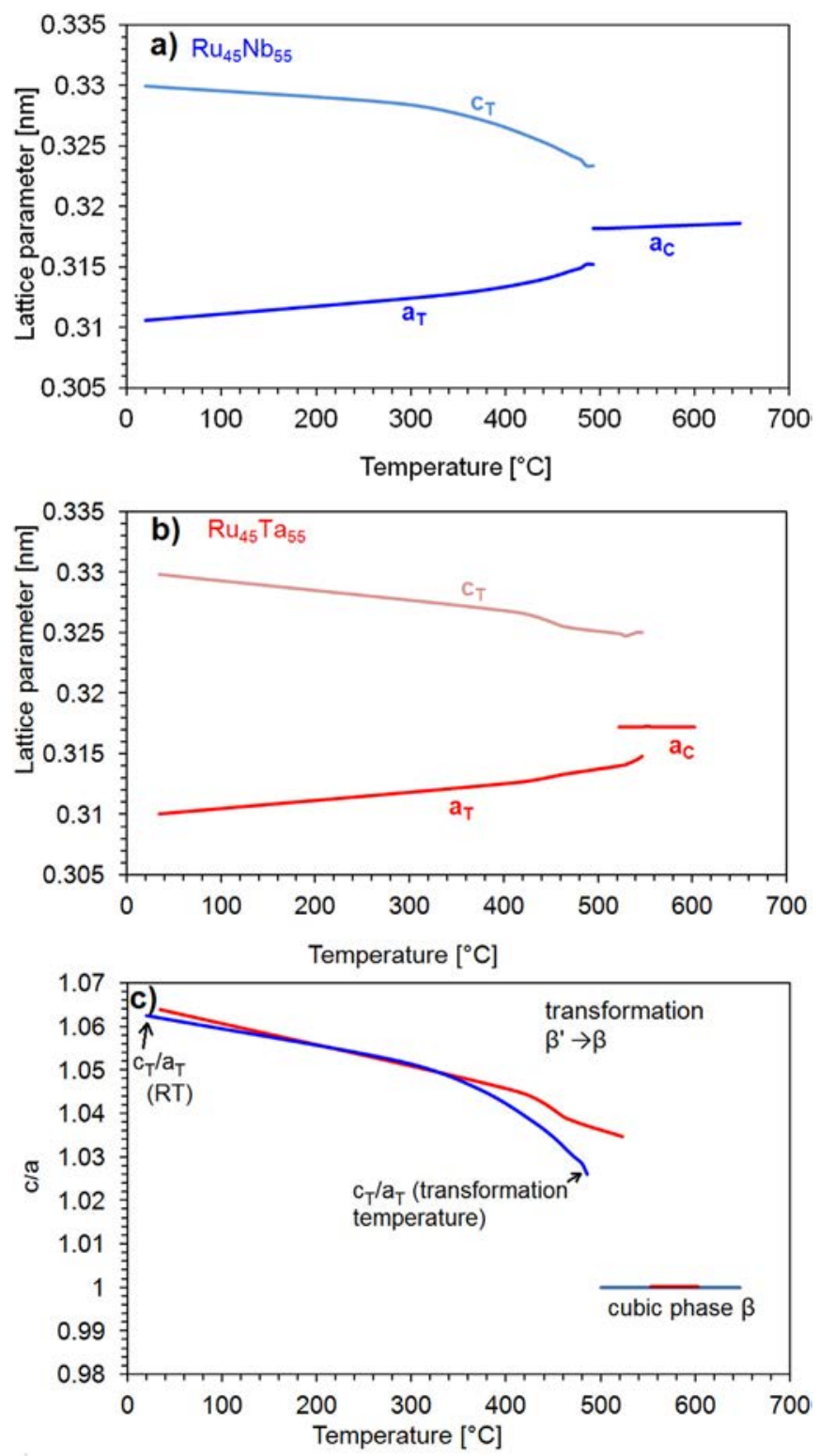

Fig. 9. Evolution of a) the lattice parameters of $\mathrm{Ru}_{45} \mathrm{Nb}_{55}$, b) the lattice parameters of $\mathrm{Ru}_{45} \mathrm{Ta}_{55}$ and c) the c/a ratio of the off-stoichiometric alloys as determined by neutron diffraction. orientation of the two phases can be described as follows:

$\mathrm{P} 4 / \mathrm{mmm}\left(\mathrm{a}_{\beta^{\prime}}, \mathrm{b}_{\beta^{\prime}}, \mathrm{c}_{\beta^{\prime}}\right) \rightarrow \mathrm{P} 2 / \mathrm{m}\left(\mathrm{a}_{\beta^{\prime \prime}}, \mathrm{b}_{\beta^{\prime \prime}}, \mathrm{c}_{\beta^{\prime \prime}}\right)$ with

$\mathrm{a}_{\beta^{\prime \prime}}=\mathrm{a}_{\beta^{\prime}}-\mathrm{b}_{\beta^{\prime}}+2 \mathrm{c}_{\beta^{\prime}}$

$\mathrm{b}_{\beta^{\prime \prime}}=-\mathrm{a}_{\beta^{\prime \prime}}-\mathrm{b}_{\beta^{\prime}}$

$\mathrm{c}_{\beta^{\prime \prime}}=\mathrm{a}_{\beta^{\prime}}-\mathrm{b}_{\beta^{\prime}}-\mathrm{c}_{\beta^{\prime}}$

There is a group - subgroup relationship between the tetragonal $\mathrm{P} 4 / \mathrm{mmm}$ and the monoclinic $\mathrm{P} 2 / \mathrm{m}$ structures, but moreover, as the two space groups are symmorphic, the decomposition into the point groups and the translations subgroups can be considered separately:

$2 / \mathrm{m} \subset 4 / \mathrm{mmm}$

$\mathrm{P}\left(\mathrm{a}_{\beta^{\prime \prime}}, \mathrm{b}_{\beta^{\prime \prime}}, \mathrm{c}_{\beta^{\prime \prime}}\right) \subset \mathrm{P}\left(\mathrm{a}_{\beta^{\prime}}, \mathrm{b}_{\beta^{\prime}}, \mathrm{c}_{\beta^{\prime}}\right)$

3.2.4.2. Stoichiometric alloys with two subsequent phase transformations

3.2.4.2.1. The tetragonal microstructure of $\beta^{\prime}$ passed on to the monoclinic microstructure of $\beta^{\prime \prime}$. Just above the second martensitic transformation temperature, the alloy is tetragonal with a twinned microstructure consisting of $A_{\beta \rightarrow \beta^{\prime}}$ and $C_{\beta \rightarrow \beta^{\prime}}$ twins or only $A_{\beta \rightarrow \beta^{\prime}}$ twins. A major characteristic of the displacive transformations, which include the martensitic transformation, is the fact that all the structural features of the parent phase are inherited by the transformed phase. In the present case, this means that the one or two laminate arrangements of the tetragonal phase will be maintained in the monoclinic phase and two neighbour laminates will remain twins, for energetic reasons. With the parameters determined at the transformation temperature, a very good correspondence between the inherited A or C twin planes formed in the tetragonal phase and simple indexed planes in the monoclinic phase is observed:

$$
\begin{aligned}
& (101)_{\mathrm{T}}=(3 \overline{1} 0)_{\mathrm{M}} \\
& (10 \overline{1})_{\mathrm{T}}=(11 \overline{2})_{\mathrm{M}} \\
& (011)_{\mathrm{T}}=(1 \overline{1} \overline{2})_{\mathrm{M}} \\
& (01 \overline{1})_{\mathrm{T}}=(310)_{\mathrm{M}}
\end{aligned}
$$

3.2.4.2.2. Orientation variants generated from the $\beta^{\prime} \rightarrow \beta^{\prime \prime}$ transformation. The group tree (Fig. 11) for this $\mathrm{P} 4 / \mathrm{mmm}$ to $\mathrm{P} 2 / \mathrm{m}$ transformation shows that there are four variants of the monoclinic phase for every twin domain of the tetragonal phase.

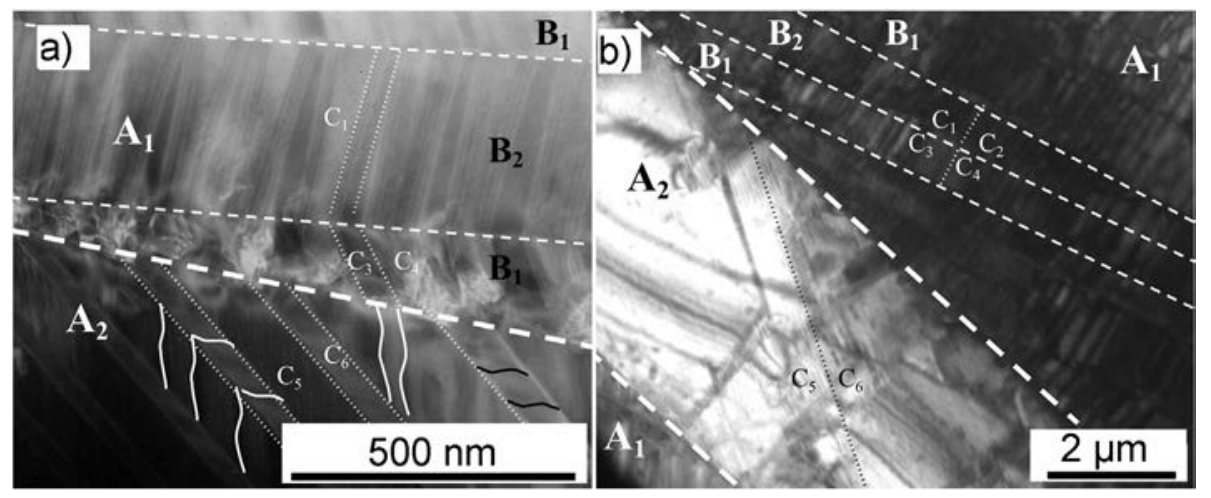

Fig. 10. a) $\mathrm{DF}$ TEM images of the monoclinic $\mathrm{Ru}_{50} \mathrm{Ta}_{50}$ and b) $\mathrm{BF}$ image of the monoclinic $\mathrm{Ru}_{50} \mathrm{Nb}_{50}$ at room temperature. 


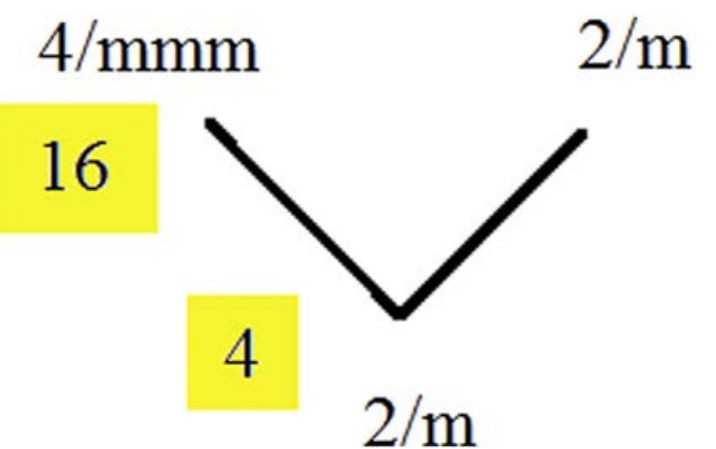

Fig. 11. Group tree showing the relationships between the $\mathrm{P} 4 / \mathrm{mmm}$ and the $\mathrm{P} 2 / \mathrm{m}$ phases.

Five mirrors belong to $4 / \mathrm{mmm}$, and only one is common with $2 /$ $\mathrm{m}$, namely $\mathrm{m}_{(110) \mathrm{M}} / / \mathrm{m}_{(1 \overline{1} 0) \mathrm{T}}$ The two fold axis of $2 / \mathrm{m}, 2_{[010] \mathrm{M}}$ is parallel to 2 [110]M. It can thus be written, bearing in mind the lost four fold axis:

$4 / \mathrm{mmm}=2 / \mathrm{m}+4_{[001] \mathrm{T}}^{1} 2 / \mathrm{m}+4_{[001] \mathrm{T}}^{2} 2 / \mathrm{m}+4_{[001] \mathrm{T}}^{3} 2 / \mathrm{m}$

The four monoclinic variants are related by three co-sets which are summarized in Fig. 12. The relations are mirrors or rotations. At the transformation temperature, an excellent match between the lost mirrors of the tetragonal phase and simple crystallographic planes of the monoclinic phase is observed. According to relations 3 the corresponding planes are the following:

$$
\begin{aligned}
& (001)_{\mathrm{T}}=(20 \overline{1})_{\mathrm{M}} \\
& (010)_{\mathrm{T}}=(111)_{\mathrm{M}} \\
& (1 \overline{10})_{\mathrm{T}}=(101)_{\mathrm{M}} \\
& (100)_{\mathrm{T}}=(1 \overline{1} 1)_{\mathrm{M}}
\end{aligned}
$$

In the monoclinic phase, the twinning interfaces can be easily characterized by transmission microscopy. Fig. 13 shows two TEM BF images. Fig. 13a shows a $C(101)_{\mathrm{T}}$ twin of the tetragonal phase transferred to the monoclinic phase where it shows a mirror symmetry $(\overline{3} 10)_{\mathrm{M}}$.

It can be noticed that the two $C$ twin variants now have very different thicknesses, which is a result from the evolution of the self-accommodated twinned structure that formed at the first transformation temperature, due to the tetragonal lattice parameter changes during cooling in the existence domain of the tetragonal phase.

Fig. 13b shows a B twin generated by the second martensitic transformation, which is described by a mirror symmetry with respect to (111) $)_{\mathrm{M}}$ and which corresponds to the lost $(010)_{\mathrm{T}}$ mirror. Note that there are two different monoclinic variants $M_{1}$ and $M_{2}$ in one same tetragonal variant $\mathrm{T}_{1}$. Thus, as any operation of a co-set transforms the reference variant into another one, it is reasonable, due to the twinned microstructure, to choose the mirror operation for the description of the interface.

\subsection{Microstructural analysis of the monoclinic $\beta^{\prime \prime}$ phase at room temperature}

Observations with the electron backscattered diffraction (EBSD) method give information about large areas of the material and the distribution of the twinned elements can thus be obtained with the relative misorientations and the operations which relate the variants.

\subsubsection{First microstructure: example of a straight $B$ twin formation}

Fig. 14 shows the first example of an EBSD investigation of a region in $\mathrm{Ru}_{50} \mathrm{Ta}_{50}$ with an $\mathrm{A}$ twin with internal $\mathrm{B}$ and $\mathrm{C}$ twins. Fig. 14a shows the quality map and Fig. 14b shows the same region recolored with green, blue and red colours (every colour family corresponds to one general direction for the $\mathrm{c}_{\mathrm{T}}$ axis). Fig. 14c shows the EBSD map recorded along the normal direction and the half

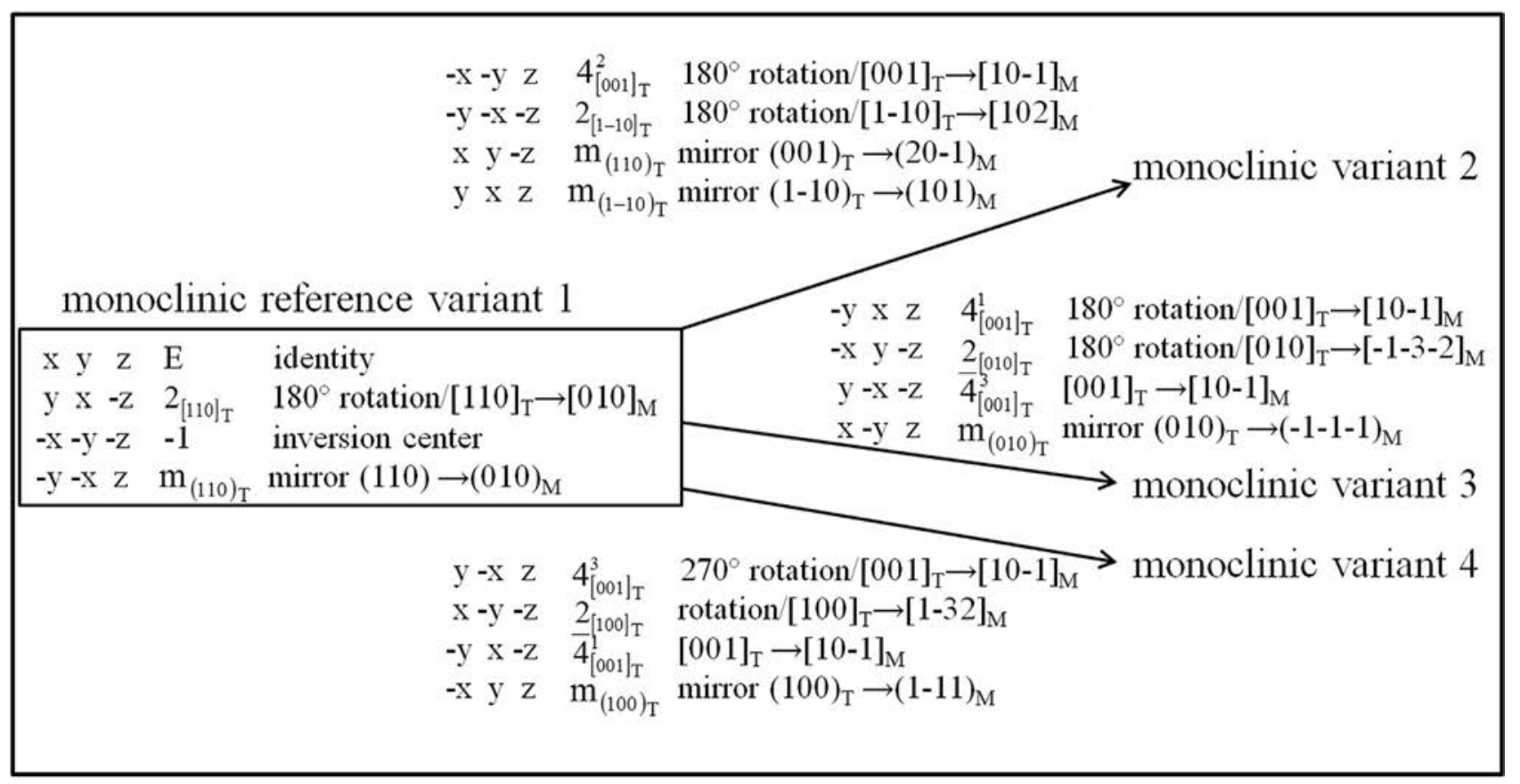

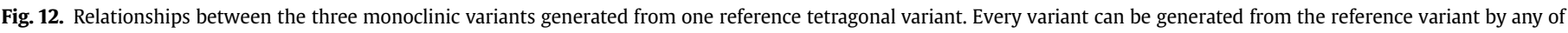
the four operation of the co-set. 


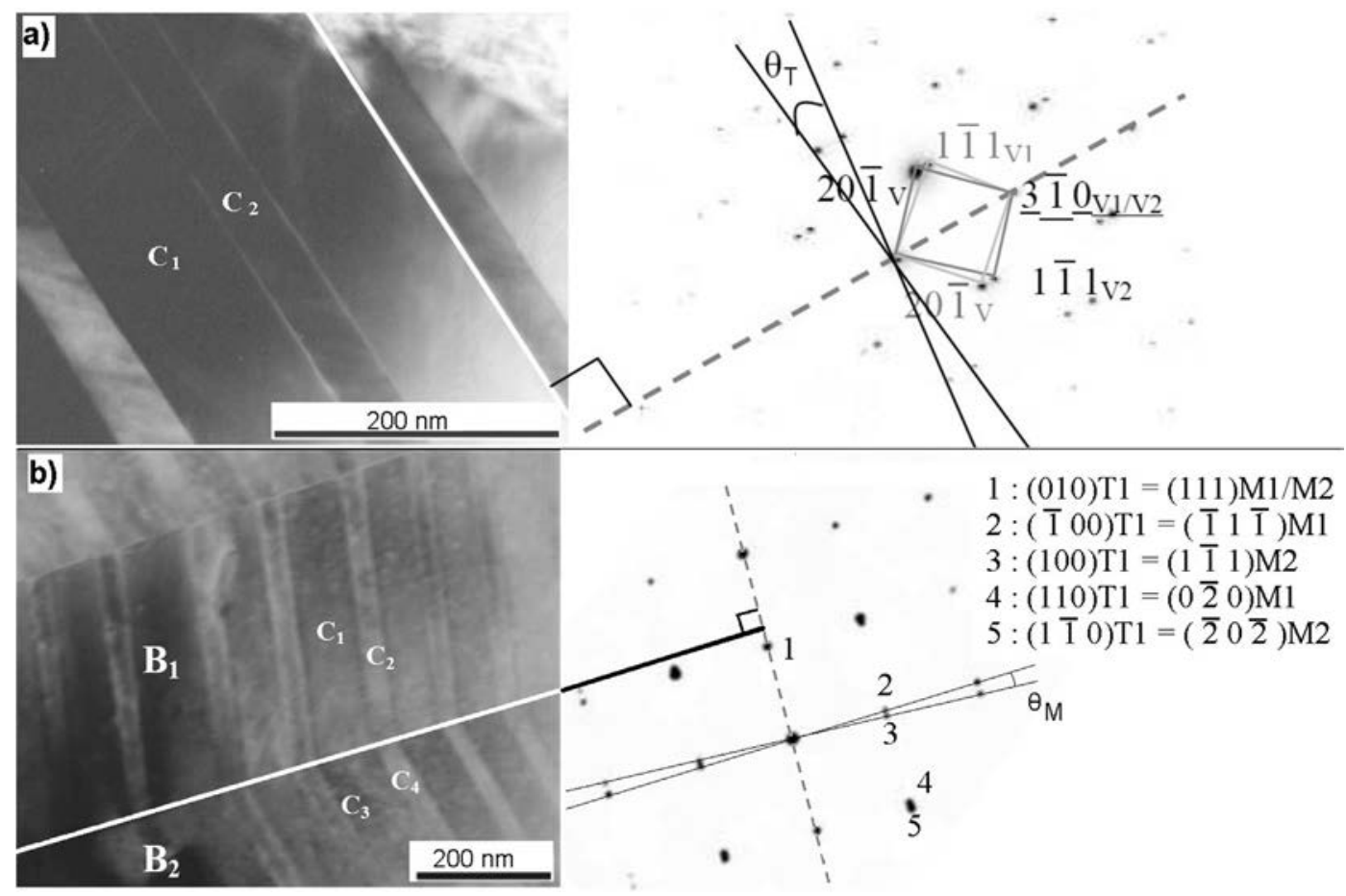

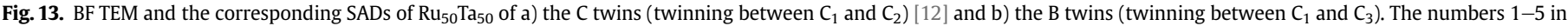
b) indicate special spots indexed in the tetragonal $(\mathrm{T})$ and the monoclinic system (M).

circle giving the colour code of the different orientations. Fig. 14d shows three pole figures which give the orientations of the tetragonal $(100)_{\mathrm{T}}$ and $(001)_{\mathrm{T}}$ planes, the colours correspond to the ones in (b). Three parallelepipeds have been drawn in the second pole figure to visualize the orientation of the inner tetragonal cell. In the pole figure according to $(001)_{M}$ the green regions have been omitted for the sake of clarity. Inside the A twin four monoclinic crystals can be identified, visualized in (b) and (d) in bright blue, dark blue, bright red and dark red. In this example the $C$ twins are continuous in shape through the B twins.

Fig. 15 schematically shows the four monoclinic crystals inside the A twin in Fig. 14. The colour code has been kept the same. Two operations link the bright red, the dark red, the bright blue and the dark blue crystal: a second martensitic transformation B twinning operation (shown in yellow) and a first martensitic transformation $\mathrm{C}$ twinning operation (shown in white). The red regions belong to one same former tetragonal variant and their twinning plane $(100)_{\mathrm{T}}$ is a lost mirror plane of the tetragonal system. The same is true for the two blue regions. This has also been visualized in the pole figures in Fig. 14. Note that the pole figure along $(100)_{M}$ shows that there is a common pole between the dark red and the bright blue crystal, as well as between the dark blue and the bright red crystal: These crystals, even though they do not belong to the same tetragonal variant, share the pole that belongs to $(001)_{\mathrm{M}}$, which is the former tetragonal $(1 \overline{11})_{\mathrm{T}}$. Instead of a mirror, considering the [4]-fold axis which belongs to the co-sets, we can say that the blue crystals are linked by a rotation of $90^{\circ}$ around the pole of their common $(20 \overline{1})_{M}$ plane, and the red crystals are also linked by a rotation of $90^{\circ}$ around the pole of their common $(20 \overline{1})_{M}$ plane. The twinning relationships are thus the same in both tetragonal variants.

Both Figs. 14 and 15 show an unexpected result: the type B twins, which are created during the second transformation $\beta^{\prime} \rightarrow \beta^{\prime \prime}$, have a larger spacing than the $C$ twins, which are created during the first transformation $\beta \rightarrow \beta^{\prime}$ and transferred into the second one $\beta^{\prime} \rightarrow \beta^{\prime \prime}$

As has been stated earlier, the $\beta^{\prime}$ tetragonal microstructure with two laminates $A_{\beta \rightarrow \beta^{\prime}}$ and $C_{\beta \rightarrow \beta^{\prime}}$, as shown in Fig. 16a will be maintained during the second transformation. A finer microstructure is then expected for the $\beta^{\prime \prime}$ monoclinic martensite (see Fig. 16b) because the four variants of $\beta^{\prime \prime}$ must be generated inside every Ctwin domain. However, new planar $\mathrm{B}_{\beta^{\prime} \rightarrow \beta^{\prime \prime}}$ twins with a larger width than the $C_{\beta \rightarrow \beta^{\prime}}$ twins are observed, as shown in Fig. 16c.

Type $C$ twins are formed by alternating two tetragonal variants during the whole stacking sequence, which leads to a periodic repetition of the local conditions for the transformation from $\beta^{\prime}$ to $\beta^{\prime \prime}$. If any residual elastic strain field exists due to an imperfect selfaccommodation after the strong evolution of the tetragonal lattice parameters, they are repeated periodically and identically along the stacking. They thus provide local constraints, which influence the nucleation of the monoclinic phase, and which orient it, repeatedly and identically in both variants that are inherited from the tetragonal phase.

The same alternation of monoclinic variants can be observed in the present case. The variants develop alternatively in one out of two $C$ twin platelets as well as in the platelets that are in a $C$ twin relationship. The variants which are linked by a $\mathrm{B}$ twin have no direct reason for favouring a continuous $B$ twin line throughout the different $C$ twins. Nevertheless, these new $B$ twins, which are linked to the formation of the monoclinic martensite, have straight interfaces which cross the stack of $C$ twins through the entire $A$ domain. In order to explain this necessity, a consideration of what might happen if the B interface was not straight can be useful (see Fig. 17). If it was not straight, some crystallographic incompatibilities would occur along the $C$ twin plane. There is no monoclinic twinning relationship between the monoclinic variants marked in dark red and in bright blue and thus they could not exist next to each other. The $C$ twins, however, do not change their shape during the $\mathrm{B}$ twinning operation. This unexpected microstructure is the consequence of the fact that the second transformation $\beta^{\prime} \rightarrow \beta^{\prime \prime}$ 

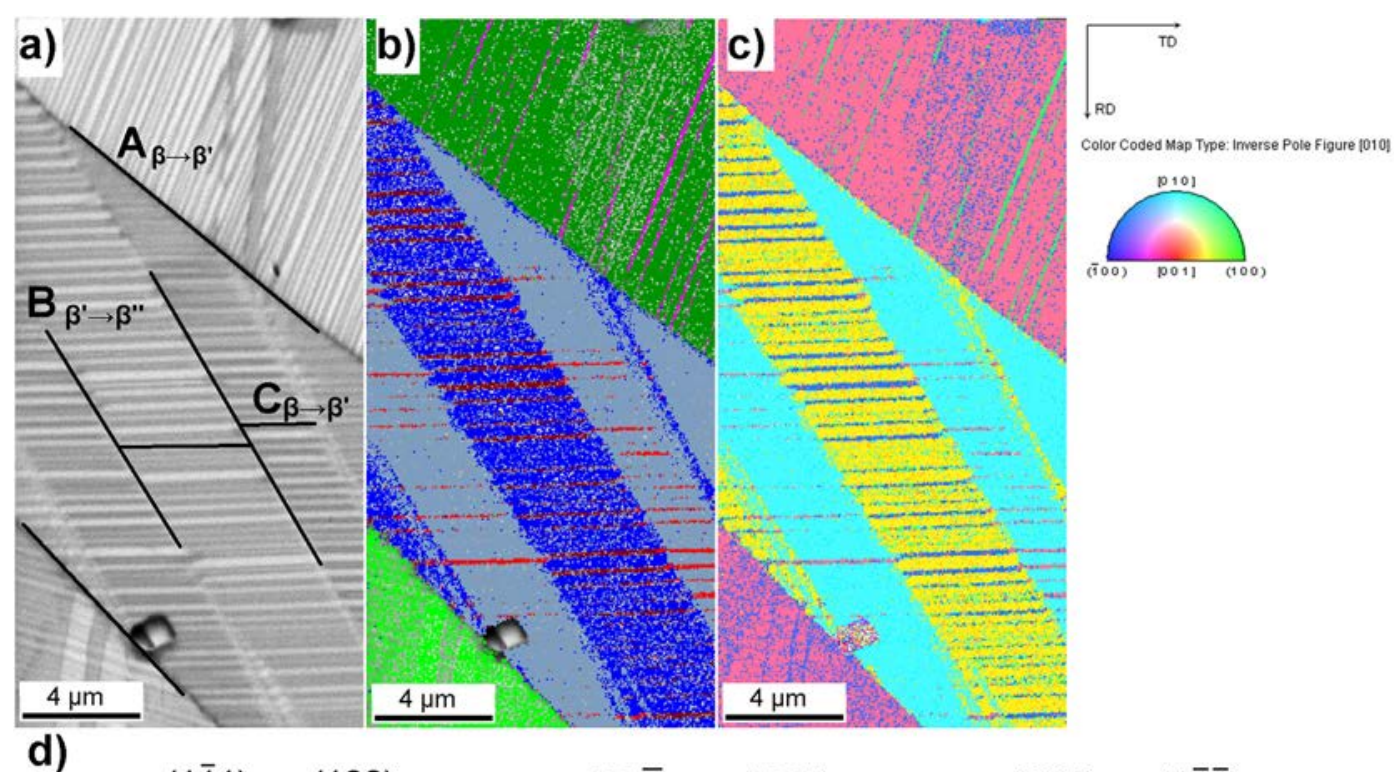

d)

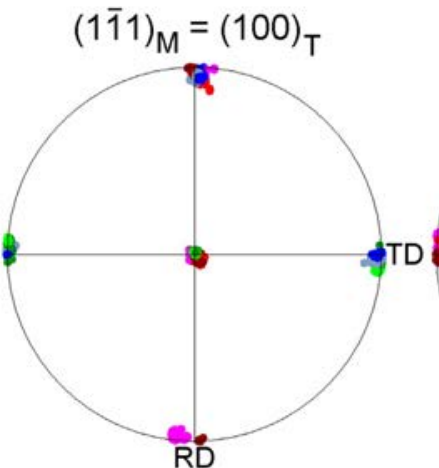

$(20 \overline{1})_{M}=(001)_{T}$

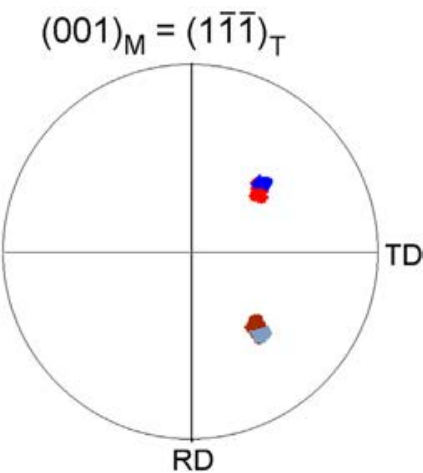

Fig. 14. EBSD observations of the monoclinic $\mathrm{Ru}_{50} \mathrm{Ta}_{50}$. (a) Quality map [16], (b) artificially recolored region (c) Colour coded map as recorded along the normal direction ND and the corresponding half circle indicating the directions (d) pole figures of three planes and three parallelepipeds showing the direction of the inner tetragonal cell.

$$
(1 \overline{1} 1)_{M}=(100)_{T}(B \text { twin })
$$

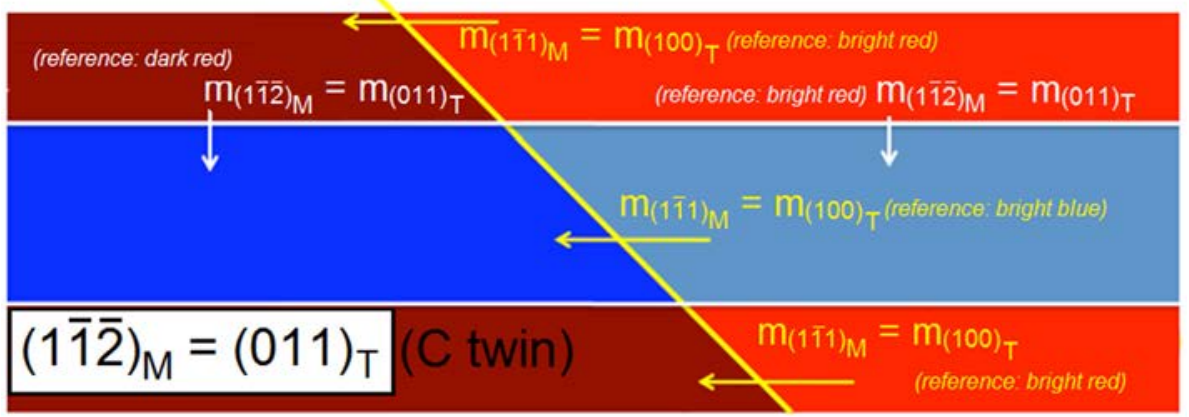

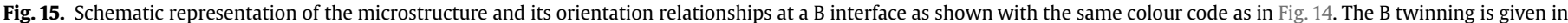

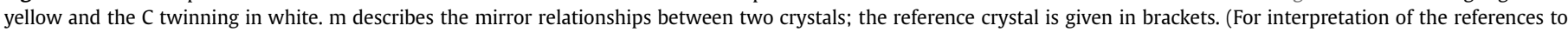
colour in this figure legend, the reader is referred to the web version of this article.)

is sterically, crystallographically and mechanically constrained.

At a given temperature the first transformation starts in the mother phase, the BCC austenite. It is supposed that the initial alloy contains little internal stress, as the cubic domain is situated at very high temperature. A possible nucleation would therefore not be influenced by any stress fields and the transformation is without constraints. The nuclei appear in the smallest unit of the mother phase, which is the grain; in an equi-probable way and they grow to create the final microstructure. In the case of shape memory alloys, such a transformation incites self-accommodating groupings inside every grain in order to reduce the deformation stress. Close to the grain boundaries the self-accommodation may be harder to 


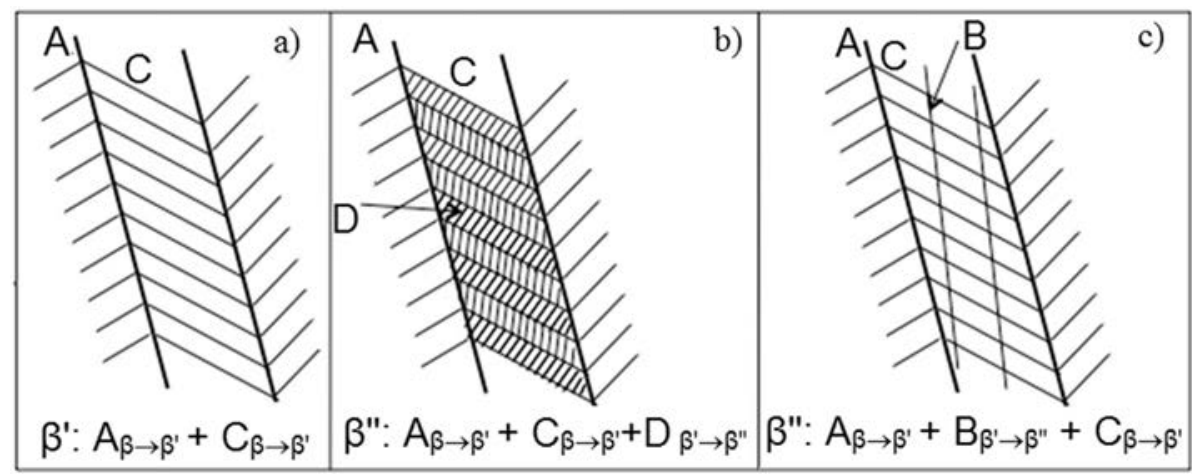

Fig. 16. Schematic representations of a) the tetragonal microstructure, b) the expected monoclinic microstructure and c) the observed monoclinic microstructure [16].

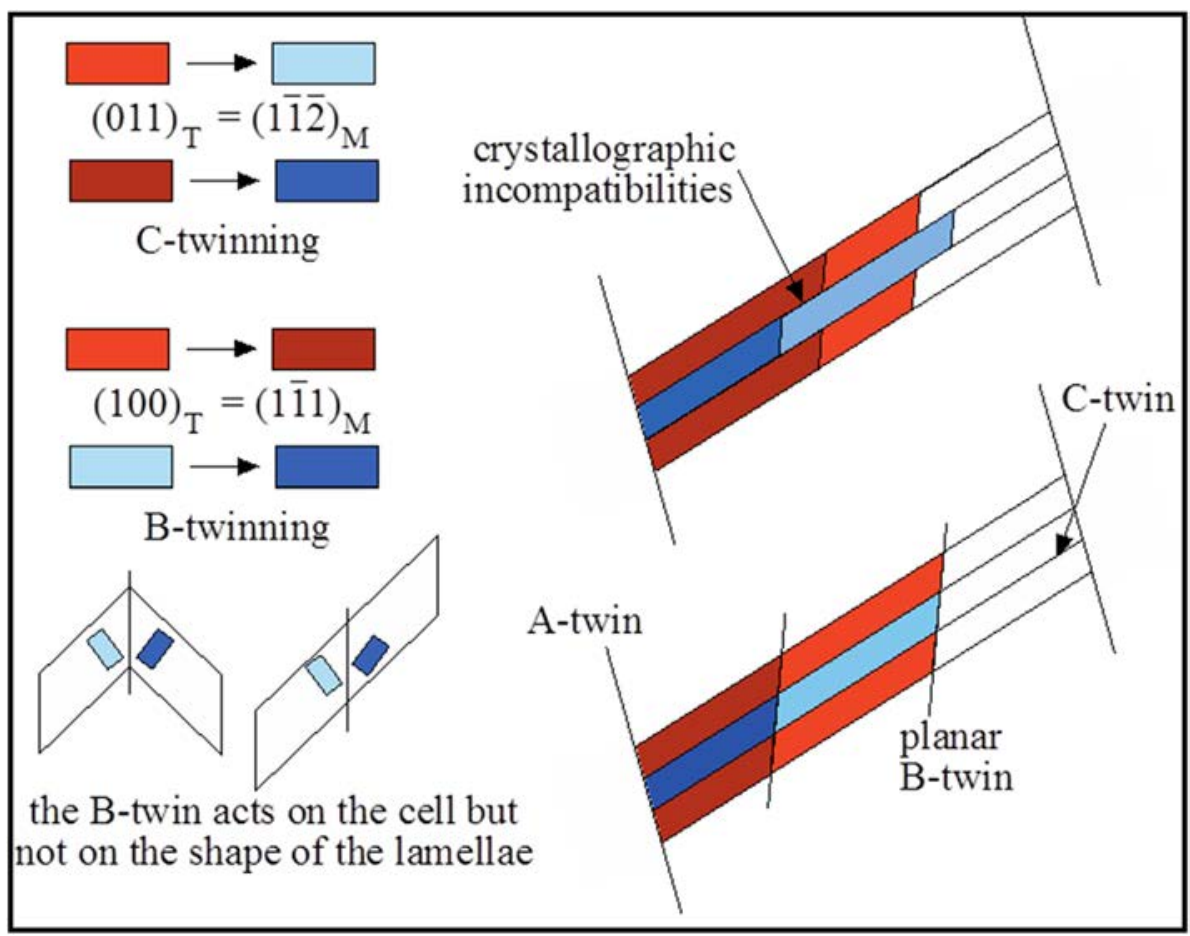

Fig. 17. Schematic view of what the microstructure would look like if the B interface was not straight and the crystallographic consequences.

achieve. For the second transformation, the conditions are different and can be summarized as follows:

- transformation with a steric constraint

This transformation is characterized by a parent phase with very small grains or at least one small dimension for the smallest unit with the same orientation, i.e. the twin lamellae. This small dimension implies a steric constraint which influences the microstructure because there is no place where the influence of the grain boundaries can be ignored. In the present case the smallest unit is the $C$ twins, and as the latter have a thickness of several nanometres, only one $\beta^{\prime \prime}$ variant is created in the direction of the thickness.

- transformations with steric and crystallographic constraints

This is the case when the region where the transformation is bound to take place is both small, at least in one dimension, and also limited by non arbitrary interfaces, e.g. planes with a precise crystallographic orientation, whose properties, like symmetry operation, must survive in the transformed phase. The influence persists until the neighbour domains are reached, which lie on the other side of the interfaces. This is called a crystallographic coherence at the interfaces' intersections where several domains need to be crystallographically linked. - Transformations with steric, crystallographic and mechanic
constraints

It is now possible to add a mechanical constraint which is supposed to play an active role in the transformation. It is due either to external stresses, which can occur in the case of stressinduced martensite, or to internal stresses, as in the case of those shape memory alloys which have been trained in order to orient the transformation, or else to residual elastic stresses which can be due to a non perfect self-accommodation. Their role becomes more important with higher steric constraints. Because of the elastic 
energy which has been stored during the crossing of the tetragonal domain and a high variation of the crystalline parameters and the $\mathrm{c} /$ a ratio, the nucleation of $\beta^{\prime \prime}$ is controlled by the alternation of the $C$ twins. The nucleation of the $\beta^{\prime \prime}$ variants reproduces identically every other $C$ variant and the twinning condition is being respected.

\subsubsection{Second microstructure: example of a zigzag $C$ twin formation}

Fig. 18 shows the second example of an EBSD investigation of a region in $\mathrm{Ru}_{50} \mathrm{Ta}_{50}$ inside an $\mathrm{A}$ twin with only $\mathrm{B}$ and $\mathrm{C}$ twins visible. Fig. 18a shows the quality map and Fig. 18b shows the same region recolored with blue and red colours (each colour family corresponds to one general direction for the $\mathrm{c}_{\mathrm{T}}$ axis). Fig. 18 shows the EBSD map recorded along the normal direction and the half circle giving the colour code of the different orientations. Fig. 18d shows three pole figures which give the orientations of the tetragonal $(100)_{\mathrm{T}}$ and $(001)_{\mathrm{T}}$ planes, the colours correspond to the ones in (b). Note that the third pole figure for $(001)_{\mathrm{M}}\left(=(1 \overline{11})_{\mathrm{T}}\right)$ is different from the one in Fig. 14. Inside the A twin four monoclinic crystals can be identified, visualized in (b) and (d) in bright blue, dark blue, bright red and dark red. In this example the $C$ twins are not continuous in shape through the B twins, they form a zigzag. This time the $C$ twinning operations concern the unit cells as well as the twinning domains.

Just as for the microstructure in Fig. 14, the important crystals have been recoloured in bright red, dark red, bright blue and dark blue in order to visualize explanations more easily.
The relationships in this microstructure have been summarized in Fig. 19. As before and as in Fig. 18, the four crystals are shown in bright red, bright blue, dark red and dark blue and they are visualized by an extract of their stereographic projection in the corresponding colour. The $\mathrm{B}$ twinning plane is shown in yellow and the $\mathrm{C}$ twinning plane in blue.

The explanation for the formation of this microstructure is different from the one in Fig. 14. It is not possible that it forms from a two laminates tetragonal phase with $A$ and $C$ twins. If the $C$ twins are straight, like in the previous microstructure in Fig. 14, a zigzag distribution cannot be generated in the monoclinic phase. If the zigzag $C$ twins existed in the tetragonal phase, a third twin system, namely $\mathrm{D}$, would be necessary but in that case, the $\mathrm{D}$ twin element would be coming from the first transformation and this is not the case.

A possible evolution of this microstructure is schematically shown in Fig. 20. It starts with a microstructure in the tetragonal phase consisting of a single twin laminate, $A$, which the selfaccommodated system generated during the $\beta \rightarrow \beta^{\prime}$ transformation at the transformation temperature (Fig. 20a). Upon cooling, the evolution of the tetragonal lattice parameters is not accommodated with a second level of twins, namely the $C$ ones. Like in the previous case with two layers of laminates, more elastic energy (stress field) will be stored by the specimen.

When the temperature of the second transformation is reached, two variants of the monoclinic phase, separated by a B-twin plane, are alternatively generated and their nucleation is stress assisted.
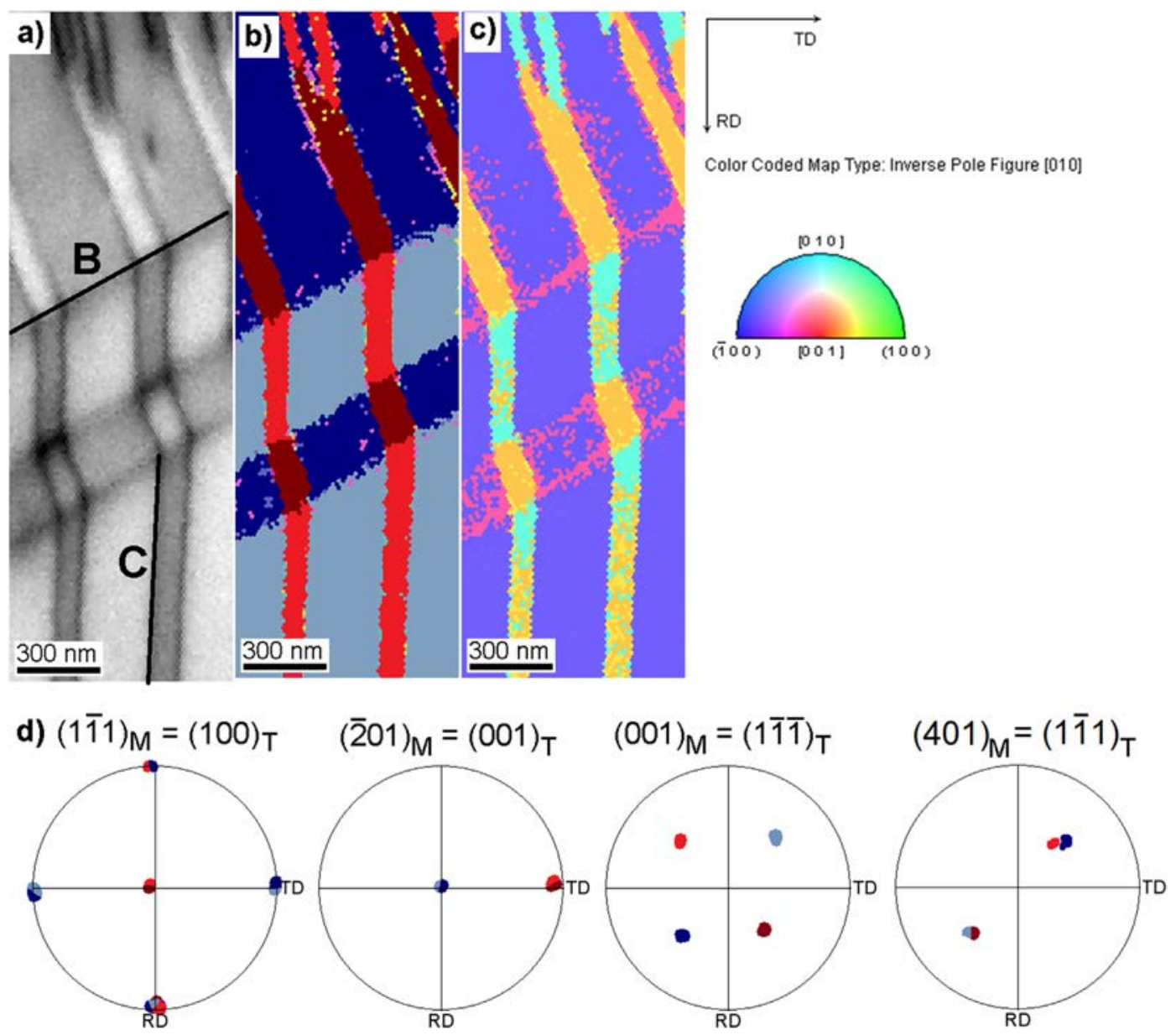

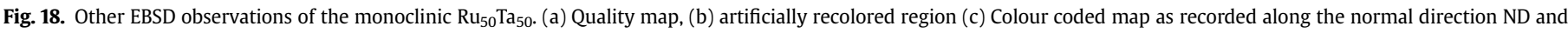
the corresponding half circle indicating the directions (d) pole figures of four planes. 


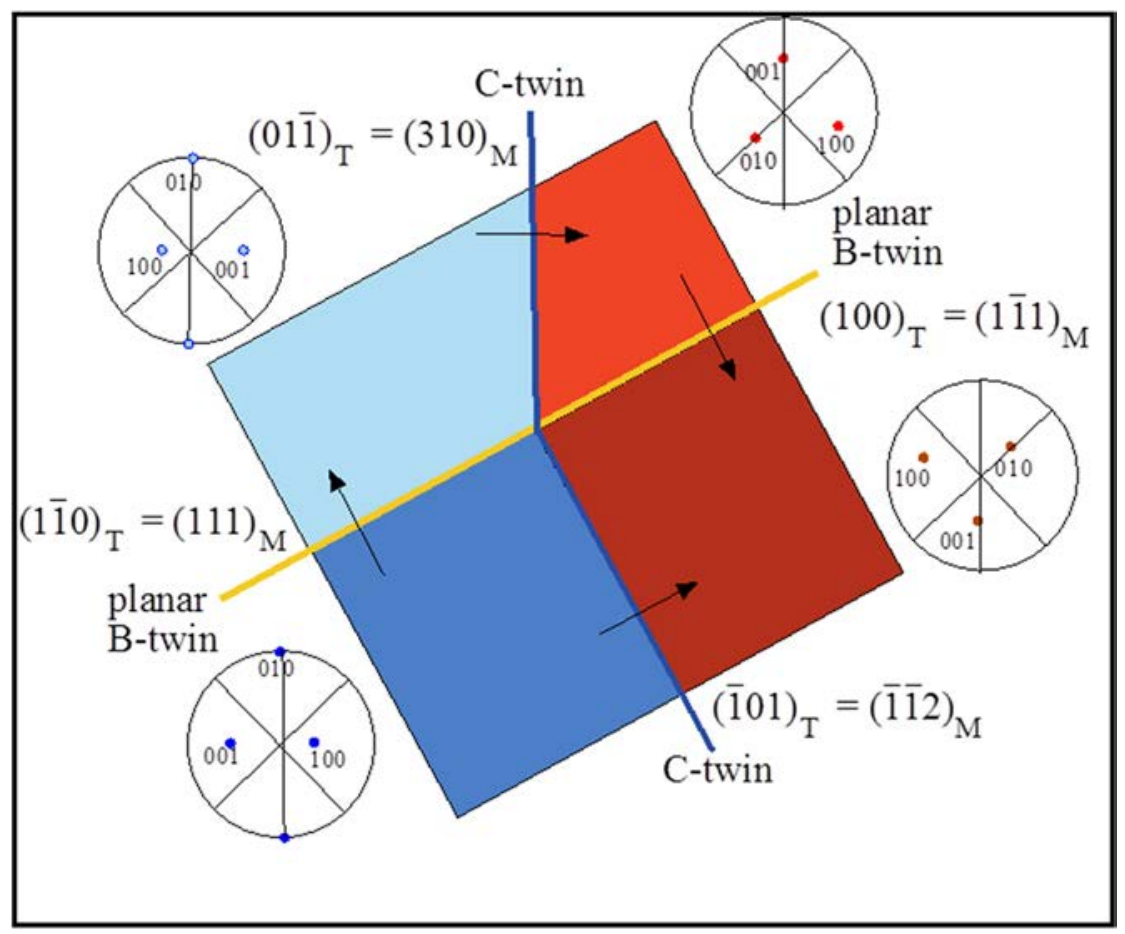

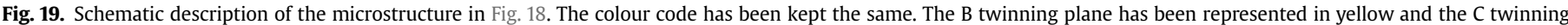

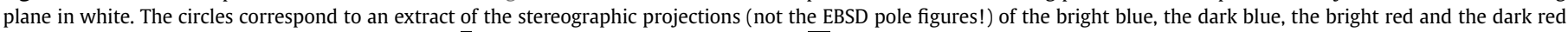

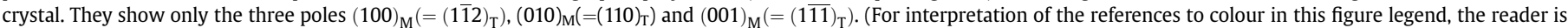
referred to the web version of this article.)

a)

b)

c)

d)

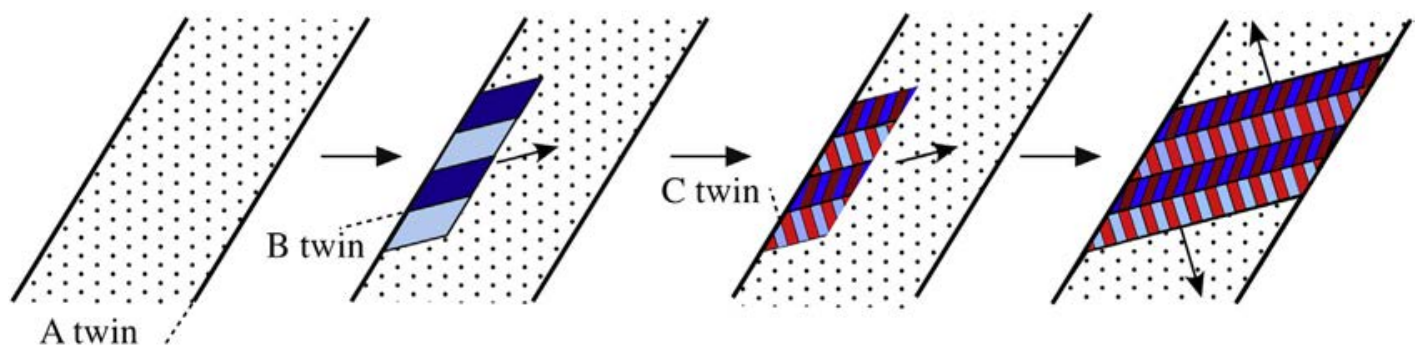

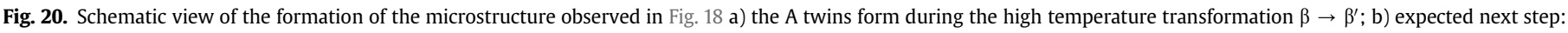

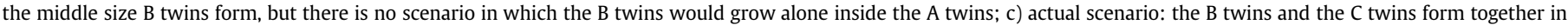
order to accommodate all the distortions; d) the final microstructure.

Nevertheless, the accommodation is not sufficient (see Fig. 20b) and some mechanical twinning is induced into the monoclinic phase. The former $\beta \rightarrow \beta^{\prime}$ twin elements, which generated the tetragonal variants and which were inherited by the monoclinic phase, are good candidates for the formation of this twinning. This is the reason for a $\mathrm{C}$ type laminate system which is now generated in the monoclinic phase during the second transformation for the relaxation of the elastic energy stored during the cooling (Fig. 20c). The zigzag configuration is due to the fact that the same events appear simultaneously in the B-twinned variants of the monoclinic structure (Fig. 20d).

\section{Summary}

The microstructure of six alloys of the Ru-Ta and Ru-Nb high temperature shape memory alloys have been analyzed in detail via scanning and transmission electron microscopy, electron backscattered diffraction and neutron diffraction. The cooling down from the cubic phase through the tetragonal phase, and, in case of the stoichiometric alloys, through the monoclinic domain, has been taken into account in order to describe the twinning formation mechanisms.

In every grain of the cubic $\beta$ phase the high temperature transformation $\beta \rightarrow \beta^{\prime}$ implies the formation of $\{101)_{\mathrm{T}}$ compound twins with large spacing $(A)$, alone or with additional ones with very small spacing $(C)$. The three types of tetragonal variants form from the cubic cell along the three main $[100]_{C}$ directions and are related to each other by the mirrors of the cubic cell that are lost during the martensitic transformation.

The low temperature transformation $\beta^{\prime} \rightarrow \beta^{\prime \prime}$, present only in the stoichiometric alloys, creates another type of twinning of intermediate spacing, called $\mathrm{B}$, with an unexpected intermediate spacing between the A and C spacing. Group theory has been used in order to explain the twin formation: out of one tetragonal variant 
four different monoclinic variants can form. They are images of each other by a mirror symmetry operation of the tetragonal cell that has been lost during the second phase transformation.

Finally, the numeration of the variants of the monoclinic phase could be done directly from the cubic phase and the twinning systems correspond to the eight (out of nine) lost mirrors of the cubic phase. The last cubic mirror corresponds to the monoclinic mirror. In these alloys the loss of the cubic mirrors takes place in two steps and the monoclinic twins are generated, not in the grains of the parent phase, but in the inherited twin domains of the tetragonal phase. For this reason, the second phase transformation is constrained, and the final microstructure is controlled by crystallographic, steric and mechanical factors.

Two main microstructures have been identified in the stoichiometric alloys at room temperature and interpreted at the light of these constrains. Two formation scenarios upon cooling have been proposed:

- In the first case, the tetragonal A and C twins have formed at the end of the tetragonal domain. When crossing into the monoclinic domain the monoclinic $B$ twins are generated and have an unexpected intermediate spacing;

- In the second case, only the tetragonal A twins have formed at the end of the tetragonal domain. The expected $B$ twins and the unexpected (for this second transformation) C twins form simultaneously, providing the observed zigzag microstructure.

Even though the shear of the unit cell that is associated with the $\beta^{\prime} \rightarrow \beta^{\prime \prime}$ transformation is smaller than the one of the $\beta \rightarrow \beta^{\prime}$ transformation, the addition of a third level of twinning provides a higher density of twinning planes, which is probably favourable to a higher shape memory effect in the monoclinic alloys. This possible correlation will be the subject of further investigations.

\section{Acknowledgements}

The authors would like to thank A. Bachelier-Locq and C. Ramusat for help with sample preparation and C. Sanchez for help with X-ray diffraction experiments. We are also grateful to D. Gratias and D. Boivin for most valuable crystallographic discussion and to G. Wallez for help with XRD investigations.

EU funding for the FIB/SEM within project "AME-Lab" (European Regional Developement Fund C/4-EFRE 13/2009/Br) is gratefully acknowledged. Authors thank the Institute Laue Langevin for beam time.

\section{References}

[1] J. Ma, I. Karaman, R.D. Noebe, High temperature shape memory alloys, Int. Mat. Rev. 55 (2010) 257-315.

[2] H. Donkersloot, J.H.V. Vucht, Martensitic transformations in gold-titanium, palladium-titanium and platinum-titanium alloys near the equiatomic composition, J. Less Common Met. 20 (1970) 83-91.

[3] V.N. Khachin, Martensitic transformation and shape memory effect in B2 intermetallic compounds of titanium, Rev. Phys. Appl. 24 (1989) 733-739.

[4] K. Otsuka, H. Sakamoto, K. Shimizu, Successive stress-induced martensitic transformations and associated transformation pseudoelasticity in Cu-Al-Ni alloys, Acta. Metall. Mater. 27 (1979) 585-601.

[5] Z. Li, Z.Y. Pan, N. Tang, Y.B. Jiang, N. Liu, A. Fang, F. Zheng, Cu-Al-Ni-Mn shape memory alloy processed by mechanical alloying and powder metallurgy, Mat. Sci. Eng. A 417 (2006) 225-229.

[6] T. Omori, W. Ito, K. Ando, K. Oikawa, R. Kainuma, K. Ishida, FCC/HCP martensitic transformation and high-temperature shape memory properties in Co-Si alloys, Mater. Trans. 47 (2006) 2377-2380.

[7] K. Otsuka, K. Oda, Y. Ueno, M. Piao, T. Ueki, H. Horikawa, The shape memory effect in a Ti50Pd50 alloy, Scr. Metall. Mater. 29 (1993) 1355-1358.

[8] T. Biggs, M.J. Witcomb, L.A. Cornish, Martensite-type transformations in platinum alloys, Mat. Sci. Eng. A 273 (1999) 204-207.

[9] R.W. Fonda, H.N. Jones, R.A. Vandermeer, The shape memory effect in equiatomic TaRu and NbRu alloys, Scr. Mater. 39 (1998) 1031-1037.

[10] R.W. Fonda, H.N. Jones, R.A. Vandermeer, The shape memory effect in ruthenium alloys, Miner. Metals Mater. Soc, Warrendale, 1999. Vol. International Symposium on Advances in Twinning, at the 1999 TMS Annual Meeting, p. 279-285.

[11] A. Manzoni, K. Chastaing, A. Denquin, P. Vermaut, R. Portier, Shape recovery in high temperature shape memory alloys based on the Ru-Nb and Ru-Ta systems, in: P. Sittner, V. Paidar, L. Heller, H. Seiner (Eds.), Esomat 2009-8th European Symposium on Martensitic Transformations, Prague, Czech Republic, 2009.

[12] X. Gao, Y.F. Zheng, W. Cai, S. Zhang, L.C. Zhao, Microstructure, compression property and shape memory effect of equiatomic TaRu high temperature shape memory alloy, J. Mat. Sci. Tech. 20 (2004) 97-99.

[13] A. Manzoni, in: Alliages à mémoire de forme hautes températures base Ru pour application turbomachines, Université Pierre et Marie Curie, Paris, France, 2011.

[14] A.M. Manzoni, A. Denquin, P. Vermaut, I.P. Orench, F. Prima, R.A. Portier, Shape memory deformation mechanisms of Ru-Nb and Ru-Ta shape memory alloys with transformation temperatures, Intermetallics 52 (2014) 57-63.

[15] P. Vermaut, A. Manzoni, A. Denquin, F. Prima, R.A. Portier, Unexpected constrained twin hierarchy in equiatomic Ru-based high temperature shape memory alloy martensite, in: S. Prokoshkin, N. Resnina (Eds.), European Symposium on Martensitic Transformations, 2013, pp. 195-199.

[16] K. Chastaing, A. Denquin, R. Portier, P. Vermaut, High-temperature shape memory alloys based on the RuNb system, Mat. Sci. Eng. A 481 (2008) $702-706$.

[17] R.W. Fonda, R.A. Vandermeer, Crystallography and microstructure of TaRu, Phil. Mag. A 76 (1997) 119-133.

[18] J. Rodriguez-Carvajal, Recent advances in magnetic structure determination by neutron powder diffraction, Phys. B 192 (1993) 55-69.

[19] E.O. Hall, Twinning and Diffusionless Transformations in Metals, Butterworths Scientific Publications, London, 1954. 